NBER WORKING PAPER SERIES

OPEN BANKING: CREDIT MARKET COMPETITION WHEN BORROWERS OWN THE DATA

Zhiguo He

Jing Huang

Jidong Zhou

Working Paper 28118

http://www.nber.org/papers/w28118

\author{
NATIONAL BUREAU OF ECONOMIC RESEARCH \\ 1050 Massachusetts Avenue \\ Cambridge, MA 02138 \\ November 2020
}

Preliminary and comments welcome; references incomplete. We thank the seminar participants at Hong Kong Shue Yan University. Zhiguo He acknowledges the financial support from the Center for Research in Security Prices at the University of Chicago Booth School of Business. All errors are ours. The views expressed herein are those of the authors and do not necessarily reflect the views of the National Bureau of Economic Research.

NBER working papers are circulated for discussion and comment purposes. They have not been peer-reviewed or been subject to the review by the NBER Board of Directors that accompanies official NBER publications.

(C) 2020 by Zhiguo He, Jing Huang, and Jidong Zhou. All rights reserved. Short sections of text, not to exceed two paragraphs, may be quoted without explicit permission provided that full credit, including $\left({ }^{\circ}\right.$ notice, is given to the source. 
Open Banking: Credit Market Competition When Borrowers Own the Data

Zhiguo He, Jing Huang, and Jidong Zhou

NBER Working Paper No. 28118

November 2020

JEL No. D18,G21,L13,L15,L51

\begin{abstract}
$\underline{\text { ABSTRACT }}$
Open banking facilitates data sharing consented by customers who generate the data, with a regulatory goal of promoting competition between traditional banks and challenger fintech entrants. We study lending market competition when sharing banks' customer data enables better borrower screening or targeting by fintech lenders. Open banking could make the entire financial industry better off yet leave all borrowers worse off, even if borrowers could choose whether to share their data. We highlight the importance of equilibrium credit quality inference from borrowers' endogenous sign-up decisions. When data sharing triggers privacy concerns by facilitating exploitative targeted loans, the equilibrium sign-up population can grow with the degree of privacy concerns.
\end{abstract}

\section{Zhiguo He}

University of Chicago

Booth School of Business

5807 S. Woodlawn Avenue

Chicago, IL 60637

and NBER

zhiguo.he@chicagobooth.edu

Jing Huang

University of Chicago

5807 South Woodlawn Ave

Chicago, Illi 60637

United States

jing.huang@chicagobooth.edu
Jidong Zhou

Yale University

165 Whitney Avenue

New Haven, CT 06511

jidong.zhou@yale.edu 


\section{Introduction}

The world is racing toward an era of open-data economy, thanks to the rapidly evolving information and digital technology. Customer data - instead of being zealously kept within individual organizations or institutions in an isolated fashion - have become more "open" to external third parties, whenever customers who generate these data consent to share them. Open banking, an initiative led by several governments, including Australia and the United Kingdom, leads such a shift toward the open-data economy. As the global discussion unfolds, many practitioners and policy makers expect "open banking" to represent perhaps the most transformative trend in the banking industry in the coming decade.

Although open banking can be viewed as part of broad endeavor by the European Union on consumer privacy protection (typified by the General Data Protection Regulation), the core principle of open banking does not stop at customer ownership of their own data, but more importantly, envision enabling customers to voluntarily share their financial data with other entities, via, say, application programming interfaces, or APIs (Second Payment Services Directive, PSD2). ${ }^{1}$ When Deloitte Insight conducted a survey on open banking in April 2019, it employed the following "descriptive" definition of open banking, which vividly captures its essence: ${ }^{2}$

Imagine you want to use a financial product offered by an organization other than your bank. This product could be anything you feel would help you, such as an app that gives you a full picture of your financial status, including expenses, savings, and investments or it could be a mortgage or line of credit. But for this product to be fully useful to you, it needs information from your bank, such as the amount of money you have coming in and going out of your accounts, how many accounts you have, how you spend your money, how much interest you have earned or paid, etc. You then instruct your bank to share this information with this other institution or app. Should you wish to stop using this product, you can instruct your bank to stop sharing your data at any given point in time, with no strings attached. This concept is called open banking.

The idea to let borrowers decide if they want to share data with some third parties - especially competing fintech lenders may have profound implications on credit market competition and welfare. To the best of our knowledge, our paper is the first to study this question theoretically. Although the role of information technology has been studied in the literature of credit market competition as

\footnotetext{
${ }^{1}$ The PSD2 in European Union mandates European banks create best practices in APIs, vendor integration, and data management. Loosely speaking, application programming interfaces, allow users to synchronize, link, and connect databases; in the context of a banking system, they link a bank's database (its customers' information) with different applications or programs, thus forming a network encouraging the promotion of services, payments, and products appropriate to each person.

${ }^{2}$ See endnote 1 on page 17 in Srinivas, Schoeps, and Jain (2019). The article is available at https://bit.1y/ $3 \mathrm{mIdm} 2 \mathrm{~N}$. Open banking regulations that require banks to share their data with third parties upon customers' consent have been implemented in Europe, Australia, and many Asian countries such as Singapore and Japan. Though no such regulation exists in the U.S. today, major banks are already implementing open data sharing through APIs which allow third parties to access to their data. Notable examples include JP Morgan Chase (https://bit.1y/3kMjB4V) and U.S. Bank (https://bit.1y/3oC4KfI).
} 
we will discuss later, our paper emphasizes that, under open banking, it is borrowers - rather than lenders - who control lenders' access to borrower information via their own data sharing decisions. This conceptual difference is the cornerstone of our analysis, and begets many interesting questions regarding the welfare implications of open banking.

We consider a traditional bank and a fintech lender in competition with each other. They conduct independent but imperfect creditworthiness tests before making loan offers to borrowers. Each borrower can have a high or low credit quality, and the test yields a binary signal of their credit quality. This framework is based on Broecker (1990) and has been widely used to study lending market competition as we will discuss later. Similar to common-value auctions, an important feature of this market is a winner's curse (i.e., winning a borrower implies the possibility that the rival lender has observed an unfavorable signal of the borrower's credit quality). This winner's curse essentially determines the lending cost. In equilibrium, the lender that has a better screening ability and so faces a less severe winner's curse earns a positive profit in expectation, while the other one with a weaker screening ability earns a zero profit and sometimes declines to extend an offer to a borrower even upon seeing a favorable signal.

This baseline credit market competition model is presented in Section 2. We use it to study the impact of open banking on market performance. Traditional banks enjoy a great advantage from a vast amount of customer data they possess (say, from transaction accounts, direct deposit activities, etc). Fintech lenders are often equipped with limited data (usually restricted to social activities and profiles), but much more advanced data analysis algorithms; without enough data, however, a better algorithm does not yield more useful information. Therefore, in our benchmark case with no open banking, we assume that the bank has a better screening ability than the fintech lender. (We define screening ability as the joint outcome of data availability and data analysis techniques.) Open banking, by allowing borrowers to share their bank data, can greatly enhance the competitiveness of the fintech lender as a "challenger."

We study two types of data that borrowers can share via open banking. The first contains information on borrowers' credit quality, which affects the lending cost of financial institutions. The other type of data potentially reveals borrowers' preferences for the fintech loan, and these "privacy" data might enable the fintech to offer targeted loans to exploit borrowers.

Section 3 examines credit-quality data sharing. Once the fintech has an access to the bank's data, we assume that its screening ability is improved. Because the fintech has a more advanced data analysis algorithm, it could even surpass the bank in screening borrowers, especially when it also has some independent data sources. ${ }^{3}$ The improvement of the fintech's screening ability has two effects: First, as the fintech now can better identify a borrower's true type, it helps high credit quality borrowers but hurts low credit quality borrowers. This is a standard "information effect." Second, it also affects the extent of winner's curse that each lender faces, and so the degree of lending competition. This "strategic effect" can go either direction: lending competition will be intensified

\footnotetext{
${ }^{3}$ For example, Berg, Burg, Gombović, and Puri (2020) provide evidence that fintech lenders use a different source of information, digital footprints, to assess customers' creditworthiness; digital footprints improve the predictive power of traditional credit bureau data when combined with the latter.
} 
(softened) if the screening ability gap between the two lenders shrinks (expands). In particular, if open banking expands the screening ability gap sufficiently (i.e., if open banking "overempowers" the fintech), it will hurt both types of borrowers but improve industry profit. Reflecting on the celebrated selling point that open banking promotes competition and benefits borrowers, we hence highlight that data sharing may backfire and increase the competitiveness of the challenger lender too much.

The key question is then: can the very nature of open banking-borrowers deciding whether to opt in to share their banking data with the fintech lender - prevent this perverse effect of open banking on borrowers from happening? After all, borrowers will not act against their own interest. Our analysis with voluntary sign-up decisions provides a negative answer to this question. We show that provided that there exist some borrowers who never sign up due to prohibitively high sign-up costs (e.g., because they do not know how to use the new technology or have strong privacy concerns), generically there exists a non-empty set of parameters under which in the only (nontrivial) equilibrium, proportionally more high-type borrowers sign up and all borrowers are left strictly worse off compared to the regime of before open banking. Those who sign up suffer due to weakened competition as a result of the enlarged lender asymmetry caused by data sharing; those who do not suffer due to an adverse equilibrium inference that opting-out signals poor credit quality.

Section 4 studies data sharing on customer preference privacy. We assume that borrowers are subject to some random shocks under which they can only take the fintech's loan. For instance, they happen to need a quick loan and only the fintech can process with "immediacy"; or they have reached the bank's borrowing limit and so can only resort to the fintech. Open banking, with the aid of big data technology that can integrate, say, borrowers' social data and digital footprints together with their bank account information, allows the fintech to identify these "privacy events." Accordingly, the fintech can better take advantage of borrowers by performing precision marketing, or in other words, "delivering the right offer at the right time to the right customer." the effect of privacy events, we assume that open banking in this case does not enhance the fintech's ability to screen the credit quality of borrowers. The borrowers in privacy events resemble the "captured" consumers in Varian (1980) who consider only one seller's offer.

When the probability of privacy events is sufficiently small, the small pool of captured borrowers is not enough to compensate the loss from the winner's curse for the fintech lender, which has an inferior screening ability. Similar to the baseline model, the fintech hence earns a zero profit in equilibrium and sometimes does not make offers to borrowers with a good signal. Its profit from captured borrowers is offset by the bank's more aggressive bidding. (This is different from Varian (1980) where any firm with some captured consumers must earn a positive profit.) Open banking

\footnotetext{
${ }^{4}$ Transaction records from the borrower's bank allow fintech lenders to infer the borrower's more detailed demographic and credit information, by analyzing, say, the income and occupation revealed from direct deposits, consumption habit, and other information. This inference, combined with browsing and location data and their much shorter loan application processing time, allows fintech lenders to assess and meet the borrower's demand of "immediacy"e.g., borrowers traveling abroad need loans in foreign currencies on the spot, or consumers on e-commerce platforms with impulse purchase needs.
} 
allows the fintech to identify borrowers in privacy events and charge them a monopoly interest rate. If there were no credit quality inference from sign-up decisions, high-type borrowers would opt out to avoid paying a predatory interest rate in privacy events, while the opposite holds for low-type borrowers who repay much less often and hence care little about the interest rate. Due to this stigma effect of associating signing up with low credit quality, nobody signs up in equilibrium after open banking.

On the contrary, when the probability of privacy events is sufficiently large, the results are rather different. Before open banking, thanks to a large pool of potential captured borrowers, the fintech now earns a positive profit and always makes an offer upon a good signal. This is particularly attractive to the low-type who only care about the chance of getting a loan - in fact, they never sign up for open banking to reveal privacy events. This leads to a favorable credit quality inference for signing-up, leading all high-type borrowers to sign up in equilibrium. Piecing this together with the previous case, we predict a rising sign-up population or widespread open-banking adoption when the probability of privacy events increases. This perhaps counterintuitive result is driven by the signaling effect of sign-up decisions.

In the case of data sharing on preference based privacy, in terms of the impact on borrower welfare, we have a similar result as in the case of data sharing on credit quality information. That is, it is possible that all borrowers suffer from open banking in equilibrium. This happens for an intermediate probability of privacy events, and again this is because sign-up decisions are intertwined with credit quality inference in equilibrium. Loosely speaking, those who sign up suffer due to being exploited in privacy events $;^{5}$ those who do not suffer due to an unfavorable credit quality inference.

\section{Related Literature}

Lending market competition with asymmetric information. Our paper is built on Broecker (1990), which studies lending market competition with screening tests. In Broecker (1990), banks are symmetric and possess the same screening ability, while both our paper and Hauswald and Marquez (2003) consider asymmetric screening abilities. ${ }^{6}$ Hauswald and Marquez (2003) study the competition between an inside bank who can conduct credit screening and an outside bank who has no access to screening. They consider the possibility of information spillover to the outside bank, which reduces the inside bank's information advantage and benefits borrowers. When open banking facilitates sharing data on customer credit quality, it has some connection to the information

\footnotetext{
${ }^{5}$ Compared to opting out, signing up for open banking makes high-type borrowers to be exploited by a monopoly interest rate in the privacy event, whereas low-type borrowers are more likely to lose the chance of receiving a loan offer in the non-privacy event.

${ }^{6}$ Lending market competition with asymmetric screening abilities is related to common-value auctions with asymmetrically informed bidders. The early papers include Milgrom and Weber (1982) and Engelbrecht-Wiggans, Milgrom, and Weber (1983); later papers such as Hausch (1987), Kagel and Levin (1999), and Banerjee (2005) explore information structures that allow each bidder to have some private information (which is the information structure adopted in Broecker (1990) and our paper). The common-valuation auction literature suggests that reducing the more-informed bidder's information advantage tends to intensify competition and improve the seller's revenue, a result emerging in our baseline model as well.
} 
spillover effect studied in Hauswald and Marquez (2003).

Our paper differs from Hauswald and Marquez (2003) in three important aspects: First, in our model, open banking can empower the fintech, the initial weak lender, so that it exceeds the traditional bank in screening ability, which can harm all borrowers. Second, an important feature of open banking, which we highlight in this paper, is that customers have the control of whether to share their data, and their sign-up decision itself can potentially reveal further creditworthiness information. Third, open banking can also reveal non-credit privacy information to the fintech lender. How this enables the fintech to make more targeted loan offers and affects lending market competition has not been investigated in the literature.

Asymmetric credit market competition can also arise from the bank-firm relationship, as a bank knows its existing customers better than a new competitor; this idea was explored by Sharpe (1990). ${ }^{7}$ In our model, information asymmetry before open banking exists for the same reason: traditional banks own the customer data that fintech lenders have no access to, so that even if fintech lenders have a better data processing algorithm, they screen borrowers less accurately.

Our paper is also related to the literature on credit information sharing among banks; e.g., Pagano and Jappelli (1993) and Bouckaert and Degryse (2006). ${ }^{8}$ More broadly, lending market competition with asymmetric information is important for studying many issues such as capital requirement (e.g., Thakor, 1996), borrowers' incentives to improve project quality (e.g., Rajan, 1992), information dispersion and relationship building (e.g., Marquez, 2002), credit allocation (e.g., Dell'Ariccia and Marquez, 2004, 2006), etc.

Fintechs. Our paper connects to the growing literature on fintech disruption (see, for instance, Vives, 2019, for a review of digital disruption in banking), in particular on fintech companies competing with traditional banks in originating loans. ${ }^{9}$ Berg, Burg, Gombović, and Puri (2020) find that even simple digital footprints are informative in predicting consumer default, as a complement source of information to traditional credit bureau scores. On studies that support the notion of a competition relationship between fintech and bank in our paper, Fuster, Plosser, Schnabl, and Vickery (2019) examine the mortgage market and provide evidence that fintech lenders' technology advantage increases origination efficiency: the automated fintech lending system results in faster processing and more elastic response to changes in borrower demand. Di Maggio and Yao (2020)

\footnotetext{
${ }^{7}$ In the two-period model analyzed in Sharpe (1990), asymmetric competition arises in the second period. The corrected analysis of the second-period competition with a mixed-strategy equilibrium is offered in Von Thadden (2004).

${ }^{8}$ These two papers differ from ours in terms of focus as well as framework. Pagano and Jappelli (1993) study a collective decision on information sharing among banks (e.g., by setting up a credit bureau) where each bank acts as a monopolist in a local market. A bank can tell its residential borrowers' types and so offers type-dependent deals, but it does not know the types of borrowers who immigrate from other markets and so has to offer them a uniform interest rate. Once customer information is shared, each bank can discriminate over different types of immigrant borrowers as well. Bouckaert and Degryse (2006) study banks' individual incentives to share customer information. They argue that an incumbent bank has a strategic incentive to share partial customer information to reduce the entry of new competitors. In our paper, the sharing of bank customer data to the fintech is faciliated by open banking regulation and importantly is controlled by customers themselves.

${ }^{9}$ Blockchain and its underlying distributed ledger technology are another important disruption force in today's financial industry that has received great attention since the launch of Bitcoin. For related work on this topic, see He and Cong (2019); Biais, BisiǍšre, Bouvard, and Casamatta (2019) and Abadi and Brunnermeier (2019).
} 
find that fintech lenders serve borrowers of decent credit quality by financing higher consumption expenditures, who then default ex post more frequently than similar borrowers with non-fintech lenders. Their paper suggests a story in which some borrowers' desire for immediate consumption with fintech loans exacerbates their self-control issues to overborrow, a point that is consistent with one interpretation of the captured customers that we study in Section $4 .{ }^{10}$ In related theory work, Parlour, Rajan, and Zhu (2020) study a bank that operates in both payment service and credit (loan) markets; the bank is a monopoly lender in the loan market, but competes with stand-alone fintechs on payment service. Parlour, Rajan, and Zhu (2020) stress that customers' payment services provide information about their credit quality. In their paper, customers know that switching their payment service to fintechs has consequences on their credit service (akin to borrowers' data-sharing decisions in our model), but there is no equilibrium credit quality inference, which plays the key role in our analysis. ${ }^{11}$

Consumer privacy. Our paper also contributes to the burgeoning literature on consumer privacy (see, for instance, Acquisti, Taylor, and Wagman, 2016; Bergemann and Bonatti, 2019, for recent surveys), and is particularly related to work on the impact of letting consumers control their own data. Recent research suggests that the market equilibrium consequence of consumer privacy choices is highly context dependent. For example, in a general equilibrium setup Jones and Tonetti (2020) argue that consumer data ownership often leads to broader data usage than in the case of firm ownership, improving welfare thanks to the non-rivalry of data use. Ichihashi (2020) considers a multi-product monopoly problem where consumers choose whether to share data about their preferences, which can be used by the seller for both product recommendations and price discrimination. ${ }^{12}$ Liu, Sockin, and Xiong (2020) examine the implications of consumer privacy when there is both a normal consumption good and a temptation good; data sharing shapes sellers' marketing schemes for reaching target consumers, which improve the efficiency of the normal good but also induce some behaviorally biased consumers to overconsume the temptation good. ${ }^{13}$

We contribute to this literature by studying consumer privacy choices in the lending market. With the interaction between credit quality information and preference information, our paper

\footnotetext{
${ }^{10}$ Buchak, Matvos, Piskorski, and Seru (2018) study the mortgage market and argue that banking regulation and technology advancement contributed to the significant growth of fintech lenders. Tang (2019) uses a regulatory change that contracts bank credit as an exogenous shock and finds that P2P platforms substitutes with bank in the consumer credit market.

${ }^{11}$ Whether a consumer switches the payment service to fintechs is driven by her bank-affinity preference, which is assumed to be independent of her credit quality type.

${ }^{12}$ Ichihashi (2020) shows that the seller has an incentive to commit to not price discriminate to encourage consumer information sharing, but this can harm consumers in equilibrium because the firm may set a higher uniform price anticipating better a match between consumers and products. Ali, Lewis, and Vasserman (2020) study a related problem but in a different setup with single-product firms and argue that sharing preference information with firms can benefit consumers by amplifying price competition.

${ }^{13}$ Liu, Sockin, and Xiong (2020) emphasizes the difference between two consumer privacy regulations, namely GDPR in EU (opt-out as the default choice) and CCPA in California (opt-in as the default choice). Our study of privacy and targeted loans in Section 4 is also related to the literature on oligopolistic price discrimination (see, for instance, the survey by Stole, 2007). In our model only the fintech lender can make targeted offers, so there is asymmetric oligopolistic price discrimination. Two major differences relative to this IO literature are: our credit market competition features the winner's curse; in our model, consumers choose whether to disclose their preference information, rather than firms deciding whether to acquire consumer information.
} 
highlights the equilibrium inference from consumers' sign-up decisions in open banking. Using data from an online travel intermediary, Aridor, Che, and Salz (2020) offer evidence that this type of inference is well founded. They show that letting privacy-conscious consumers opt out of data sharing under GDPR increases the average value of the remaining consumers to advertisers.

\section{The Baseline Model}

This section introduces the basic model of credit market competition that will be used as a building block in later sections when we study open banking. Table 1 in Appendix A.1 provides a detailed list of the notation used in this paper. All proofs are found in the Appendix.

\section{$2.1 \quad$ Borrowers}

There is a continuum of risk-neutral borrowers of measure one. Each is looking for a loan that is normalized to be 1 . Borrowers differ in their default risk: a fraction $\theta \in(0,1)$ of them are high-type $(h)$ borrowers who will repay the loan with probability $\mu_{h} \in(0,1]$, and the rest $1-\theta$ of them are low-type $(l)$ borrowers who will repay the loan with probability $\mu_{l}<\mu_{h}$. Each borrower's type is that borrower's private information, but the type distribution is publicly known. Let

$$
\tau \equiv \frac{\theta}{1-\theta}
$$

be the likelihood ratio of high-type over low-type borrowers in the population, which represents the average credit quality in the market.

We assume that the interest rate in the market never exceeds $\bar{r}$. There are at least two interpretations of this assumption. Borrowers can be small business firms, each having a project in which to invest but differing in the probability that their project will succeed. When the project succeeds, it yields a net return $\bar{r}$, which is observable and contractible; when it fails, it yields nothing. As a result, borrowers will never accept a loan with an interest rate above $\bar{r}$. Alternatively, borrowers can be ordinary consumers who need a loan to purchase a product but differ in the probability that they will be able to repay the loan. (For instance, a consumer will default if she becomes unemployed, and consumers face different unemployment risks.) In this case we assume that the utility from consuming the product is sufficiently high for each type of consumer, ${ }^{14}$ but the interest rate is capped at $\bar{r}$ either due to interest rate regulation (e.g., usury laws) that prohibits excessively high rates of interest, ${ }^{15}$ or because of some exogenous outside options.

\footnotetext{
${ }^{14}$ In this case, for a borrower of type $i \in\{h, l\}$, denote by $u_{i}$ the utility from consuming the product. We assume that $\delta_{i} \equiv u_{i}-\mu_{i}(1+\bar{r}) \geq 0$ so that both types of consumers are willing to borrower at interest rate $\bar{r}$. Also see related discussions toward the end of Section 2.3.

${ }^{15}$ Usury laws prohibit lenders from charging borrowers excessively high interest rates on loans. In the U.S., many states have established caps on the interest rate that lenders can charge for small dollar loans, such as payday and auto-title products. See, for instance, https://bit.1y/3mhJn2b for details.
} 


\subsection{Lenders and Screening Ability}

There are two risk-neutral competing lenders in the market. When a borrower applies for a loan, each lender conducts an independent creditworthiness test before deciding whether to make an offer. We are interested in the case when one lender has a better screening ability than the other. As we emphasized in the introduction, screening ability includes both data availability and the data processing technique/algorithm. We call one of the lenders a strong lender (denoted by $s$ ) and the other a weak lender (denoted by $w$ ). When it comes to the open banking applications in next sections, the two lenders will be a traditional bank and a fintech lender, which differ in their screening ability.

Following Broecker (1990), we assume that each lender receives an independent and private signal of a borrower's type via a credit screening. Let $S_{j} \in\{H, L\}$ denote lender $j$ 's signal, where $j \in\{s, w\}$. Lender $j$ 's screening features a signal structure

$$
\mathbb{P}\left(S_{j}=H \mid h\right)=x_{j}^{h}, \mathbb{P}\left(S_{j}=L \mid l\right)=x_{j}^{l},
$$

with $x_{s}^{i}>x_{w}^{i}, i \in\{h, l\}$. That is, when a borrower is of high type, lender $j$ will receive a high signal $H$ with probability $x_{j}^{h}$ and a low signal $L$ with probability $1-x_{j}^{h}$; when the borrower is of low type, the bank will receive a low signal $L$ with probability $x_{j}^{l}$ and a high signal $H$ with probability $1-x_{j}^{l}$. Hence $\left(x_{j}^{h}, x_{j}^{l}\right)$ represents lender $j$ 's screening ability, which is publicly known and measures the informativeness of lender $j$ 's signal. ${ }^{16}$ In the following, we use high (low) signals and good (bad) signals exchangeably.

After receiving their private signals, the lenders update their beliefs about the borrower's type and make their loan offers $r_{j} \in[0, \bar{r}]$ (if any) simultaneously. The borrower will choose the offer with the lower interest rate. (When the two lenders offer the same deal, suppose the borrower will randomly pick one offer, though the details of the tie-breaking rule do not affect our analysis.) For simplicity, we assume that the two lenders have the same funding costs which we normalize to $1 .{ }^{17}$

\subsection{Simplifications}

To reduce the number of parameters without losing our main insights, we simplify the model by assuming: (i) $\mu_{l}=0$ and $\mu_{h}=1$. That is, a low-type borrower never repays a loan while a high-type borrower always repays; ${ }^{18}$ (ii) $x_{s}^{h}=x_{w}^{h}=1$. That is, to either lender, a high-type borrower always yields a good signal, so we have a "bad-news" signal structure. In other words, in our model a bad signal perfectly reveals that a borrower is of low type (and so no lender will lend to a borrower

\footnotetext{
${ }^{16}$ Broecker (1990) considers a general number of lenders with symmetric screening abilities, while we consider a duopoly case with asymmetric screening abilities.

${ }^{17}$ When it comes to open banking applications, we could alternatively assume that the fintech lender has a higher financing cost than the traditional bank. The fintech's disadvantageous position in financing cost is a well-known empirical regularity, because of their lack of cheap and stable funding sources like deposits. However, considering asymmetric funding costs only complicates the analysis without adding significant economic insight given our focus.

${ }^{18}$ Although low-type borrowers always default, we assume that they prefer a cheaper loan, which can be justified if $\mu_{l}$ is slightly above zero.
} 
with a bad signal), while a good signal is inconclusive. From now on, we let

$$
x_{s}=x_{s}^{l}>x_{w}=x_{w}^{l},
$$

which summarizes the two lenders' screening abilities.

We assume that each lender is willing to lend to a borrower with a high signal $H$ at the highest possible interest rate $\bar{r}$. The details of this assumption are as follows. For lender $j$, the chance that it will see a high signal from a borrower is $\theta+(1-\theta)\left(1-x_{j}\right)$. Given $\mu_{l}=1$ and $\mu_{h}=0$, upon seeing a high signal it expects a repayment rate

$$
\frac{\theta}{\theta+(1-\theta)\left(1-x_{j}\right)}=\frac{\tau}{\tau+1-x_{j}}
$$

where recall $\tau=\frac{\theta}{1-\theta}$. The lender is willing to lend at $r=\bar{r}$ if this expected repayment rate times $1+\bar{r}$ is greater than the cost 1 . This requires

$$
\tau \bar{r}>1-x_{j}
$$

This is easier to hold when there are more high-type borrowers in the population, i.e., a higher $\tau$, or when the screening ability is better. This assumption, together with the bad-news signal structure, implies that in our model the only mistake lenders may make is lending to a low-type borrower.

Finally, we assume that any borrower of type $i$ obtains a non-monetary benefit $\delta_{i}$ just from getting a loan. For high-type borrowers, they are left with some endogenous rent thanks to lender competition. We hence normalize $\delta_{h}$ to 0 for convenience as $\delta_{h}$ plays no role in our subsequent analyses. We, however, set $\delta_{l}=\delta>0$. In the context of small business loans, $\delta$ can be interpreted as the control rent of entrepreneurs from non-pledgeable income (see, for instance, Tirole, 2010), so that low-type borrowers who never succeed still care about the likelihood of getting a loan. This makes low-type borrowers' welfare meaningful, and for our applications we think about the control rent $\delta$ as relatively small. ${ }^{19}$

\subsection{Equilibrium Characterization}

We solve the model in closed-form in this section by fully characterizing the unique (mixed-strategy) equilibrium for credit market competition.

\subsubsection{Preliminary analysis}

Let

$$
p_{H H} \equiv \mathbb{P}\left(S_{s}=H, S_{w}=H\right)=\theta+(1-\theta)\left(1-x_{s}\right)\left(1-x_{w}\right)
$$

\footnotetext{
${ }^{19}$ For the interpretation of consumption loans, $\delta$ then represents the low-type borrowers' utility from consuming the product given $\mu_{l}=0$. Following the discussion in footnote 14 , we only need $\delta \geq 0$ so $\delta$ can be arbitrarily small.
} 
be the probability that both lenders observe a good signal from a borrower, and let

$$
\mu_{H H} \equiv \frac{\theta}{p_{H H}}
$$

be the probability of repayment of a borrower conditional on that. Similarly, denote by

$$
p_{H L} \equiv \mathbb{P}\left(S_{s}=H, S_{w}=L\right)=(1-\theta)\left(1-x_{s}\right) x_{w}
$$

the probability that the strong lender observes a good signal but the weak one observes a bad signal, and by

$$
p_{L H} \equiv \mathbb{P}\left(S_{s}=L, S_{w}=H\right)=(1-\theta) x_{s}\left(1-x_{w}\right)
$$

the probability that the stronger observes a bad signal but the weak one observes a good signal. In either case, the expected repayment probability is zero. Note that $p_{L H}>p_{H L}$ given that $x_{s}>x_{w}$.

The credit market competition in our model has a flavor of common-value auctions. A lender wins a borrower if it offers a better interest rate than its rival, or if the rival does not make an offer at all, which happens when it sees a bad signal. Hence, winning the borrower brings some bad news - a winner's curse. More precisely, suppose that the two lenders offer the same interest rate $r \leq \bar{r}$. Then the strong lender's profit, for instance, is

$$
p_{H H} \times \frac{1}{2}\left[\mu_{H H}(1+r)-1\right]-\underbrace{p_{H L}}_{\text {winner's curse }} .
$$

When both observe a good signal from a borrower (which occurs with probability $p_{H H}$ ), the strong lender wins the borrower with probability $1 / 2$; when the strong lender observes a good signal but the weak one observes a bad signal (which occurs with probability $p_{H L}$ ), the former wins for sure but in that case the borrower must be of low type and so will never repay the loan.

Due to this winner's curse, it is easy to see that in our model there is no pure-strategy equilibrium. ${ }^{20}$ As shown in the Online Appendix B.1, any mixed-strategy equilibrium in our model is well behaved. Let $m_{j}, j \in\{s, w\}$, be lender $j$ 's probability that it makes an offer to a borrower upon seeing a good signal. (As we will see, in the mixed-strategy equilibrium, the strong lender will always make an offer after seeing a good signal, while the weak lender will sometimes not make an offer.) Let $F_{j}(r) \equiv \operatorname{Pr}\left(r_{j} \leq r\right)$ be lender $j$ 's interest rate distribution conditional on making an offer, and as shown in Appendix B.1, the two lenders' distributions must share the same support with common lower bound $\underline{r}$ (which will be specified below) and upper bound $\bar{r}$. For our subsequent analysis, it is more convenient to use the survival function $\bar{F}_{j}(r) \equiv 1-F_{j}(r)$. Let $\pi_{j}$ be the lender $j$ 's equilibrium (expected) profit.

\footnotetext{
${ }^{20}$ It is impossible that the two lenders offer different interest rates; otherwise the lender offering a lower interest rate could always raise its interest rate slightly without losing any demand. If they charge the same interest rate and make a nonnegative profit, then the first portion in (2) must be strictly positive, in which case each lender will have a unilateral incentive to undercut its opponent.
} 
In a mixed-strategy equilibrium, the strong lender's indifference condition, when $r \in[\underline{r}, \bar{r}]$, is

$$
p_{H H}\left[1-m_{w}+m_{w} \bar{F}_{w}(r)\right]\left[\mu_{H H}(1+r)-1\right]-p_{H L}=\pi_{s} .
$$

When the strong lender offers interest rate $r$ upon seeing a good signal, there are two possibilities: if the weak lender also observes a good signal (which occurs with probability $p_{H H}$ ), the strong lender wins if the weak one does not make an offer (which occurs with probability $1-m_{w}$ ) or if the weak one makes an offer but its interest rate is above $r$ (which occurs with probability $m_{w} \bar{F}_{w}(r)$ ); if the weak lender observes a bad signal instead (which occurs with probability $p_{H L}$ ) and hence makes no offer, the borrower must be of low type and so the strong lender make a loss of 1 . Similarly, the weak lender's indifference condition is

$$
p_{H H}\left[1-m_{s}+m_{s} \bar{F}_{s}(r)\right]\left[\mu_{H H}(1+r)-1\right]-p_{L H}=\pi_{w} .
$$

Lemma 1. In any mixed-strategy equilibrium, the strong lender makes a strictly positive profit $\pi_{s}>0$ while the weak lender makes a zero profit $\pi_{w}=0$.

This is because the weak lender faces a higher lending cost due to its more severe winner's curse (i.e., $p_{L H}>p_{H L}$ ). Given that there is no product differentiation, only the lender with the lower cost makes a positive profit. As we will see below, the strong lender's profit actually equals $p_{L H}-p_{H L}=(1-\theta)\left(x_{s}-x_{w}\right)$.

\subsubsection{Mixed-strategy competition equilibrium}

Now we fully characterize the mixed-strategy equilibrium with $\pi_{s}>\pi_{w}=0$. The strong lender must always make an offer upon seeing a good signal (i.e., $m_{s}=1$ ) because of its strictly positive profit. Equation (4) then simplifies to

$$
p_{H H} \bar{F}_{s}(r)\left[\mu_{H H}(1+r)-1\right]-p_{L H}=0 .
$$

To make this equation hold for $r$ close to $\bar{r}$, we need $F_{s}$ to have a mass point at the top. Let $\lambda_{s} \equiv \lim _{r \uparrow \bar{r}} \bar{F}_{j}(r) \in[0,1)$ be the size of the mass point. (This also implies that the support of $F_{w}$ must be open at the top.) From (3) and (5), we can uniquely solve for all four endogenous variables $\left(\underline{r}, \pi_{s}, m_{w}, \lambda_{s}\right)$ and the two distributions. For notational convenience, we define

$$
\phi(r) \equiv \frac{p_{L H}}{p_{H H}\left[\mu_{H H}(1+r)-1\right]}=\frac{x_{s}}{\frac{\tau}{1-x_{w}} r-1+x_{s}},
$$

which is $\bar{F}_{s}(r)$ solving (5). Note that $\phi(r)$ depends on primitive parameters $x_{w}, x_{s}$, and $\tau$.

Denote by $\Delta$ the gap in screening ability between the two lenders:

$$
\Delta \equiv x_{s}-x_{w}
$$


One can also check that $1-\phi(\bar{r})>0$ from assumption (1), which implies that $\phi(\bar{r}) \in(0,1)$. Then the mixed-strategy equilibrium is characterized as follows:

Proposition 1. The competition between the two lenders has a unique equilibrium in which:

1. the strong lender makes a profit $\pi_{s}=\frac{\Delta}{1+\tau}$ and the weak lender makes a zero profit $\pi_{w}=0$;

2. the strong lender always makes an offer upon seeing a high signal $\left(m_{s}=1\right)$, and its interest rate is randomly drawn from the distribution $\bar{F}_{s}(r)=\phi(r)$, which has support $[\underline{r}, \bar{r}]$ with $\underline{r}=\frac{1-x_{w}}{\tau}$ and has a mass point of size $\lambda_{s}=\phi(\bar{r})$ at $\bar{r}$; and

3. the weak lender makes an offer with probability $m_{w}=1-\phi(\bar{r})$ upon seeing a high signal, and when it makes an offer the interest rate is randomly drawn from the distribution

$$
\bar{F}_{w}(r)=\frac{\phi(r)-\phi(\bar{r})}{1-\phi(\bar{r})}
$$

which has support $[\underline{r}, \bar{r})$.

When $\tau$ goes to $\infty$ (i.e., when there is no default risk in the market), as expected the equilibrium smoothly converges to the Bertrand equilibrium where both lenders offer $r=0$. One useful observation is that for $r \in[\underline{r}, \bar{r})$, the two distributions satisfy

$$
F_{s}(r)=m_{w} F_{w}(r)
$$

Since $m_{w}=1-\phi(\bar{r})<1$, this means the strong lender charges an interest rate higher than the weak lender in the sense of first-order stochastic dominance (FOSD). Intuitively, the weak lender knows that its screening ability is relatively low and a good signal is not convincing enough to determine that the borrower is of high type, and so it chooses not to lend sometimes. As a result, the strong lender sometimes acts as a monopoly credit supplier and charges a higher interest rate.

The following result reports how each lender's screening ability and average credit quality affect the competition.

Corollary 1. In the competition equilibrium,

1. when the screening ability gap $\Delta$ increases or the average credit quality $\tau$ decreases, the strong lender's profit (which is also the industry profit) increases; and

2. when the strong lender's screening ability $x_{s}$ improves, or the weaker lender's screening ability $x_{w}$ deteriorates, or the average credit quality $\tau$ decreases, both lenders charge a higher interest rate in the sense of FOSD, and the weak lender makes an offer less frequently conditional on seeing a high signal.

This result suggests that the winner's curse is the key driver of the degree of competition in our model. When the screening ability gap $\Delta$ is larger, the winner's curse becomes more asymmetric 
between the two lenders, which softens competition. When the average credit quality $\tau$ is smaller, the winner's curse for each lender becomes more severe, which also weakens competition.

Before leaving this section, we point out that Proposition 1 applies to the (generic) case of $x_{s}>x_{w}$. However, the edge case $x_{s}=x_{w}$ is slightly trickier. There are two asymmetric equilibria (which are the continuous limits of the equilibrium in Proposition 1), depending on which lender always makes an offer upon seeing a good signal. There is also a symmetric equilibrium where neither lender always makes an offer upon seeing a good signal (i.e., $m_{s}=m_{w}<1$ ). Lenders make a zero profit in any of these equilibria, but borrowers prefer the two asymmetric equilibria because there they are more likely to get a loan. For this reason, whenever this edge case matters, we focus on the asymmetric equilibria.

\subsection{Borrower Surplus}

The surplus of each type of borrowers is important for our subsequent analysis. Let $V_{i}\left(x_{w}, x_{s}, \tau\right)$ denote the expected surplus of an $i$-type borrower, $i \in\{h, l\}$, as a function of the two lenders' screening abilities and the average credit quality in the market.

A high-type borrower receives at least one offer (from the strong lender) and so always get a loan. The expected interest rate she pays is given by

$$
\left(1-m_{w}\right) \mathbb{E}\left[r_{s}\right]+m_{w} \mathbb{E}\left[\min \left(r_{w}, r_{s}\right)\right]=\underline{r}+(\bar{r}-\underline{r}) \phi(\bar{r}),
$$

where $\phi(\cdot)$ is defined as in (6). Here, when the weak lender does not make an offer, the borrower accepts the strong lender's offer; when both make offers, the borrower chooses the cheaper one. The

equality comes from using $\mathbb{E}\left[r_{s}\right]=\underline{r}+\int_{\underline{r}}^{\bar{r}} \bar{F}_{s}(r) d r$ and $\mathbb{E}\left[\min \left(r_{w}, r_{s}\right)\right]=\underline{r}+\int_{\underline{r}}^{\bar{r}} \bar{F}_{s}(r) \bar{F}_{w}(r) d r$. Then a high-type borrower's expected surplus is

$$
V_{h}\left(x_{w}, x_{s}, \tau\right)=(\bar{r}-\underline{r})(1-\phi(\bar{r})) .
$$

It is the high-type's pecuniary payoff from the project and equals $\bar{r}$ net of the expected interest rate in (8).

Since a low-type borrower never pays back her loan, she cares only about the chance of getting a loan. A low-type borrower will not receive any offer if the strong lender observes a bad signal and at the same time the weak lender either observes a bad signal or observes a good signal but does not make an offer. This occurs with probability $x_{s}\left[x_{w}+\left(1-x_{w}\right)\left(1-m_{w}\right)\right]$. Therefore, given $m_{w}=1-\phi(\bar{r})$, a low-type borrower's expected surplus is

$$
V_{l}\left(x_{w}, x_{s}, \tau\right)=\delta\left[1-x_{s}\left(x_{w}+\left(1-x_{w}\right) \phi(\bar{r})\right)\right]
$$

where $\delta$ is the low-type's non-monetary benefit from getting a loan as we have introduced before for the low-type borrower.

For our open banking applications, it is important to understand how each lender's screening 
ability affects borrower surplus.

Proposition 2. Both types of borrower benefit from a higher average credit quality $\tau$ in the market. Regarding screening ability, both types of borrower suffer due to a higher screening ability of the strong lender (i.e., a higher $x_{s}$ ); high-type borrowers also benefit from a higher screening ability of the weaker lender (i.e., a higher $x_{w}$ ), but low-type borrowers benefit from a higher screening ability of the weaker lender (i.e., a higher $x_{w}$ ) if and only if $\frac{\bar{r}}{r}<1+\sqrt{x_{s}}$.

The first result is straightforward from Corollary 1: A higher average credit quality lessens the winner's curse and so intensifies competition, and it also increases the chance that the weak lender makes an offer upon seeing a good signal. The high-type benefit from both effects and the low-type benefits from the second.

The intuition for the second result is as follows: When $x_{s}$ is improved, the screening ability gap $\Delta$ widens and this softens competition, and at the same time, the weak lender makes an offer less likely as it faces a more severe winner's curse. The high type suffers due to both effects and the low-type suffers due to the second. On the other hand, when $x_{w}$ is improved, the ability gap $\Delta$ shrinks and this intensifies competition, and at the same time the weak lender is more likely to make an offer upon seeing a good signal (but for a low type borrower, the chance of generating a good signal declines). The high type benefits from both effects and the low type can be ambiguously affected by the second effect.

In general, a change in screening ability brings about an informational effect, which enhances the screening efficiency; and a strategic pricing effect that affects the equilibrium interest rate as well as the likelihood of a loan offer from the weak lender upon a good signal. ${ }^{21}$ These two effects can be more clearly seen if we rewrite the borrower surplus in the parameter space $\left\{x_{w}, \Delta, \tau\right\}$, in which case $x_{w}$ is regarded as some base screening ability for both lenders, as formally stated in the next corollary. When $x_{w}$ increases, both lenders' screening abilities improve, and intuitively this should benefit the high type and harm the low type. On the other hand, a widening of the screening ability gap $\Delta$ worsens the winner's curse problem, and this has a strategic pricing effect which lessens competition and impairs the welfare of borrowers.

Corollary 2. Once expressed as functions of $\left\{x_{w}, \Delta, \tau\right\}, V_{h}$ increases while $V_{l}$ decreases in the base screening ability $x_{w}$, and both $V_{h}$ and $V_{l}$ decrease in the screening ability gap $\Delta$.

\section{Open Banking: Credit Information Sharing}

From now on, we consider a competition between a traditional bank (denoted by $b$ ) and a fintech lender (denoted by $f$ ). We assume that before open banking regulation, the bank is better at screening borrowers because of its rich data from existing bank-customer relationships. More

\footnotetext{
${ }^{21}$ In our setup with $\mu_{h}=1$ and $\mu_{l}=0$, the first informational effect vanishes for the high-type borrowers since they always generate a good signal, and the interest rate effect in strategic pricing vanishes for the low-type borrowers since they never repay the loan.
} 
specifically, let $x_{j}, j \in\{b, f\}$, be lender $j$ 's screening ability. We assume $x_{f}<x_{b}$ before open banking. After open banking, if the fintech has access to customer data from the bank, we assume that its screening ability improves significantly to $x_{f}^{\prime}$ so that it exceeds the traditional bank's ability $x_{b}$. This is because, for example, the fintech is often equipped with more advanced technology to make use of the data, or it has some additional customer information (e.g., from social media) that complements the bank data. Therefore, in this section we assume

$$
x_{f}<x_{b}<x_{f}^{\prime}
$$

We aim to examine the welfare impacts of open banking and will mainly focus on the possibility that open banking has a perverse effect on borrowers. In the following, we first consider the case when the data sharing is mandatory (i.e., the data will be shared even without customers' consent), and then consider the case of voluntary sign-up for data sharing as it works in practice.

\subsection{Mandatory Sign-up}

Suppose that all borrowers are required to sign up for open banking. This improves the fintech's screening ability, but it does not cause market segmentation since all borrowers have to share their data and so the lenders' prior beliefs of the average credit quality remain unchanged. This is not the practice of open banking regulation, but it is a useful benchmark.

Before open banking, the traditional bank is the strong lender and earns a positive profit $\frac{\Delta}{1+\tau}=\frac{x_{b}-x_{f}}{1+\tau}$, and the fintech earns a zero profit; after open banking, the fintech becomes the strong lender and earns a positive profit $\frac{\Delta^{\prime}}{1+\tau}=\frac{x_{f}^{\prime}-x_{b}}{1+\tau}$, and the bank earns a zero profit. Therefore, open banking increases industry profit if and only if it widens the screening ability gap between the two lenders (i.e. if $\Delta^{\prime}>\Delta$ ).

Open banking increases the weak lender's screening ability from $x_{f}$ to $x_{b}$ and may expand or shrink the screening ability gap between the two lenders. So its impact on borrowers is less straightforward. Open banking benefits borrowers of type $i \in\{h, l\}$ if and only if $V_{i}\left(x_{b}, x_{f}^{\prime}, \tau\right)>$ $V_{i}\left(x_{f}, x_{b}, \tau\right)$. (Recall that the first dependent variable in the borrower surplus function is the weak lender's screening ability.) Proposition 2 implies that for a fixed $x_{b}$, (i) $V_{h}$ increases in $x_{f}<x_{b}$ but decreases in $x_{f}>x_{b}$, and (ii) $V_{l}$ can vary with $x_{f}<x_{b}$ non-monotonically but must decrease in $x_{f}>x_{b}$. Figure 1 depicts a numerical example of how $V_{h}$ (Panel A) and $V_{l}$ (Panel B) vary with $x_{f}$ for $x_{b}=0.5$.

Therefore, if $x_{f}$ is sufficiently close to $x_{b}$ before open banking and $x_{f}^{\prime}$ is sufficiently above $x_{b}$ after open banking, both types of borrowers suffer from open banking. In other words, open banking is detrimental to all borrowers if it causes a significantly larger new asymmetry between lenders. It is also useful to think of the borrower surplus problem from the perspective of the base screening ability $x_{w}$ and the ability gap $\Delta$ as in Corollary 2. Open banking improves the base screening ability, which benefits the high type but harms the low type. Hence, the high type will suffer from open banking only if it widens the gap (i.e. if $\Delta^{\prime}>\Delta$ ), in which case the low type must suffer from 


\section{Figure 1: Borrower Surpluses when Fintech Screening Ability Varies}
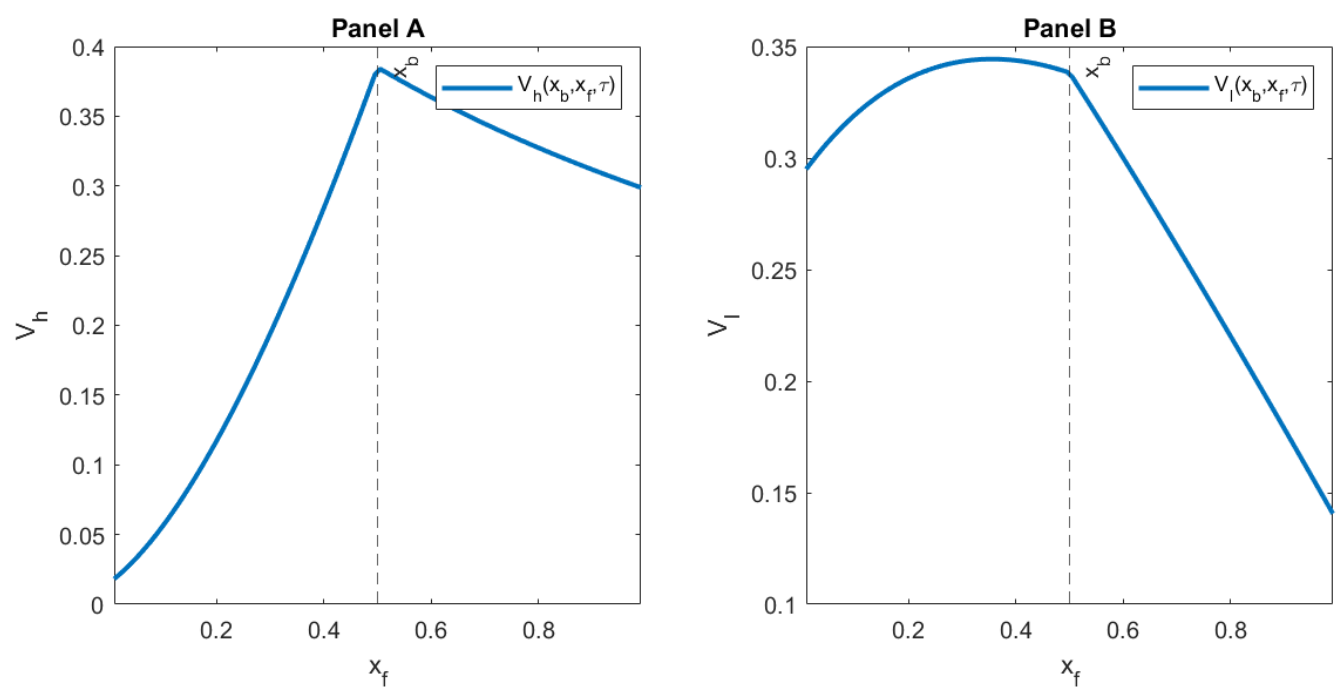

Panel A plots the high-type borrower surplus $V_{h}\left(x_{b}, x_{f}, \tau\right)$ and Panel B plots the low-type borrower surplus $V_{l}\left(x_{b}, x_{f}, \tau\right)$, both as functions of the fintech lender's screening ability $x_{f}$. The high-type borrower surplus $V_{h}\left(x_{b}, x_{f}, \tau\right)$ is single-peaked at $x_{f}=x_{b}$ (hence $\Delta=0$ ) while $V_{l}\left(x_{b}, x_{f}, \tau\right)$ is hump-shaped in the range of $x_{f}<x_{b}$. Parameter values are $\bar{r}=1, x_{b}=0.5, \delta=0.5$, and $\tau=1.1$.

open banking while industry profit must be boosted.

In our setup, high-type borrowers always get a loan in either regime, implying that open banking is efficiency neutral to these borrowers. Low-type borrowers' surplus is proportional to the chance that they get a loan, and so whenever they suffer from open banking, it must be that these low-type borrowers are less likely to get a loan, which improves the market efficiency if there is an efficiency loss associated with them (which is the case as long as the low-type private benefit of receiving a loan $\delta<1)$.

The above discussion is summarized in the following result:

Proposition 3. Compared to the regime before open banking,

1. for a fixed $x_{b}<1$, there exist $\hat{x}_{f}<x_{b}<\hat{x}_{f}^{\prime}$ such that open banking with mandatory data sharing harms all borrowers if $x_{f} \in\left[\hat{x}_{f}, x_{b}\right]$ and $x_{f}^{\prime} \geq \hat{x}_{f}^{\prime}$; and

2. open banking with mandatory data sharing helps the fintech but harms the bank, and whenever it harms all borrowers, it improves industry profit and market efficiency (if a low-type borrower generates an efficiency loss whenever she gets a loan).

Here we have focused on the potential perverse effect of open banking on borrowers. Of course, for other configurations of the parameters it is possible for open banking to benefit one or both types of borrower. 


\subsection{Voluntary Sign-up}

We now turn to the more realistic and also more interesting case when signing up for open banking is voluntary. Complying with the principles of GDPR in the EU (i.e., it is the customers, not the bank or the firm more generally, who own their personal data), the UK open banking regulation gives consumers the right to decide whether to allow fintech firms to access their personal banking data. But does this voluntary sign-up necessarily imply that consumers never get hurt? Consumers' sign-up decisions may reveal information on their credit quality, and this endogenous credit quality inference will influence the lenders' pricing strategies. As a result, it is ex ante unclear that open banking with voluntary sign-up always helps consumers.

To facilitate our analysis where the equilibrium credit quality inference plays a key role, whenever we study the voluntary sign-up equilibrium, we suppose that borrowers have heterogeneous sign-up costs for open banking. More specifically, a fraction $\rho \in(0,1)$ of borrowers, whom we call "non--tech-savvy," face an infinite sign-up cost and hence never sign up in equilibrium, while the remaining $1-\rho$ of borrowers, whom we call "tech-savvy," have a zero sign-up cost and their sign-up decisions will be our focus. The sign-up cost is borrowers' private information, and for model parsimony, we assume it is independent of their credit quality type.

Although we label them based on "tech-savviness", we emphasize that the distribution of signup costs captures a wide range of heterogeneity among open banking customers. For instance, some consumers are technology savvy, so that they not only "understand" the concepts of how technology works but also willing to "encompass" the utilization of such modern technology; some consumers may deeply worry about the security of sharing their own data due to some unpleasant personal experience. Our analysis does not depend on the exact interpretation of the sign-up cost.

\subsubsection{Sign-up decisions and equilibrium}

Let $\sigma_{i} \in[0,1]$, for $i \in\{h, l\}$, be the fraction of $i$-type tech-savvy borrowers who choose to sign up for open banking. Throughout, we use the two words "opt in" and "sign up" interchangeably (hence, "opt out" is equivalent to "not sign up").

Consistent with open banking in practice, we assume that a borrower's sign-up decision is observable to both lenders. ${ }^{22}$ Then the two lenders compete in two separate market segments: one where borrowers sign up for open banking, and the other where borrowers do not. Let $\tau_{+}$and $\tau_{-}$be respectively the lenders' updated prior on the average credit quality in the two market segments. Specifically,

$$
\left\{\begin{array}{l}
\tau_{+} \equiv \frac{\operatorname{Pr}[h \mid \text { sign up }]}{1-\operatorname{Pr}[h \mid \text { sign up }]}=\tau \cdot \frac{\sigma_{h}}{\sigma_{l}} \\
\tau_{-} \equiv \frac{\operatorname{Pr}[h \mid \text { not sign up }]}{1-\operatorname{Pr}[h \mid \text { not sign up }]}=\tau \cdot \frac{1-(1-\rho) \sigma_{h}}{1-(1-\rho) \sigma_{l}}
\end{array},\right.
$$

Intuitively, when high-type tech-savvy borrowers are more likely to sign up for open banking, the lenders raise their estimate of the average credit quality in the opt-in segment but lower their

\footnotetext{
${ }^{22}$ The fintech of course observes the sign-up decision. It is also easy for the traditional bank to monitor borrowers' sign-up decisions since in practice the fintech needs to use the API provided by the bank to access the customer data.
} 
estimate in the other.

Anticipating the equilibrium sign-up decisions in the population and the subsequent competition outcome in each market segment, an $i$-type borrower's sign-up decision is governed by:

$$
\begin{cases}\sigma_{i}=1, & \text { if } V_{i}\left(x_{b}, x_{f}^{\prime}, \tau_{+}\right)>V_{i}\left(x_{f}, x_{b}, \tau_{-}\right), \\ \sigma_{i} \in[0,1], & \text { if } V_{i}\left(x_{b}, x_{f}^{\prime}, \tau_{+}\right)=V_{i}\left(x_{f}, x_{b}, \tau_{-}\right), \\ \sigma_{i}=0, & \text { if } V_{i}\left(x_{b}, x_{f}^{\prime}, \tau_{+}\right)<V_{i}\left(x_{f}, x_{b}, \tau_{-}\right) .\end{cases}
$$

If a borrower chooses to sign up, she will be classified in the market segment characterized by $\left(x_{b}, x_{f}^{\prime}, \tau_{+}\right)$where the fintech becomes the strong lender; otherwise, she will be classified in the market segment characterized by $\left(x_{f}, x_{b}, \tau_{-}\right)$where the fintech remains as the weak lender. Note also that the surplus of an $i$-type non-tech-savvy borrower is $V_{i}\left(x_{f}, x_{b}, \tau_{-}\right)$, since she never signs up for open banking.

An equilibrium with voluntary sign-up is a collection of $\left\{\left\{\sigma_{i}\right\},\left\{\tau_{+}, \tau_{-}\right\},\left\{m_{j}^{+}, F_{j}^{+}\right\},\left\{m_{j}^{-}, F_{j}^{-}\right\}\right\}$, together with some off-equilibrium beliefs whenever appropriate, so that (i) $\left\{\sigma_{i}\right\}$ are the sign-up decisions of tech-savvy borrowers described in (13), (ii) $\left\{\tau_{+}, \tau_{-}\right\}$are the lenders' updated prior of the average credit quality in each market segment as determined in (12), and (iii) $\left\{m_{j}^{+}, F_{j}^{+}\right\}$and $\left\{m_{j}^{-}, F_{j}^{-}\right\}$are the lenders' equilibrium pricing strategies described in Proposition 1 respectively in the sign-up market segment characterized by $\left(x_{b}, x_{f}^{\prime}, \tau_{+}\right)$and in the opt-out market segment characterized by $\left(x_{f}, x_{b}, \tau_{-}\right)$.

Although we do not intend to fully characterize all possible equilibria for the whole range of parameters, we can rule out some types of equilibria immediately. First, it is impossible to have an equilibrium where signing up perfectly reveals the borrower type. This is the case when only high-type borrowers sign up (i.e., $\sigma_{l}=0$ and $\sigma_{h}>0$ ), or when only low-type borrowers sign up (i.e., $\sigma_{l}>0$ and $\sigma_{h}=0$ ). In the former case, a low-type borrower has an incentive to deviate and sign up so that she will be treated as a high-type borrower and so get a loan for sure; in the latter case, a low-type borrower who signs up will never get a loan and so she has an incentive to deviate. Second, the following lemma rules out the equilibrium where both types of borrowers are indifferent about whether to sign up or not. Intuitively, high-type borrowers are not afraid of a more precise screening technology, and so they are more willing to sign up than low-type borrowers.

Lemma 2. If low-type tech-savvy borrowers are indifferent between signing up or not, then high-type tech-savvy borrowers must strictly prefer to sign up.

There is always an equilibrium in which nobody signs up for open banking, if we assign a sufficiently unfavorable off-equilibrium belief to whoever signs up for open banking. ${ }^{23}$ But this equilibrium is trivial in the sense that open banking has no impact at all on borrowers and lenders. In the following, we ignore this uninteresting equilibrium. Another possible simple equilibrium is

\footnotetext{
${ }^{23}$ If the condition in Proposition 3 holds (i.e. when mandatory sign-up makes all borrowers worse off), the offequilibrium belief can be just the prior $\tau$. This can be justified, for example, if there are some fintech lovers (with the same credit quality distribution as the entire population) who always sign up for open banking.
} 
that all tech-savvy borrowers sign up for open banking (while lenders keep their prior $\tau$ in each market segment), which requires $V_{i}\left(x_{b}, x_{f}^{\prime}, \tau\right) \geq V_{i}\left(x_{f}, x_{b}, \tau\right)$ for both $i=h, l$. That is, this type of equilibrium is sustained if both borrowers benefit from open banking with mandatory sign-up; in later analysis, we will follow Proposition 3 below to rule out such equilibrium.

Only two possible types of equilibria remain: one with $\sigma_{h}=1$ and $\sigma_{l} \in(0,1)$ in which the lenders' updated prior in the sign-up market segment is $\tau_{+}>\tau$ (i.e., signing-up is a signal favoring high type), and the other with $\sigma_{l}=1$ and $\sigma_{h} \in(0,1)$ in which the lenders' updated prior in the sign-up market segment is $\tau_{+}<\tau$ (i.e., signing-up is a signal favoring low type). Intuitively, the first type of equilibrium is more sensible since high-type borrowers are more willing to face a fintech with a higher screening ability. In the following, we explore the possibility that all borrowers suffer from open banking in this type of equilibrium.

\subsubsection{Perverse impact of open banking}

To sustain an equilibrium with $\sigma_{h}=1$ and $\sigma_{l} \in(0,1)$, we need

$$
V_{h}\left(x_{b}, x_{f}^{\prime}, \tau_{+}\right) \geq V_{h}\left(x_{f}, x_{b}, \tau_{-}\right)
$$

and

$$
V_{l}\left(x_{b}, x_{f}^{\prime}, \tau_{+}\right)=V_{l}\left(x_{f}, x_{b}, \tau_{-}\right),
$$

where $\tau_{+}>\tau>\tau_{-}$. The latter condition also implicitly requires that the opt-out market segment be active, i.e.,

$$
\tau_{-} \bar{r}>1-x_{f} .
$$

In this equilibrium, all low-type borrowers (regardless of their sign-up cost) must be harmed by open banking since $V_{l}\left(x_{f}, x_{b}, \tau_{-}\right)<V_{l}\left(x_{f}, x_{b}, \tau\right)$ given $\tau_{-}<\tau$. All high-type borrowers will suffer as well if

$$
V_{h}\left(x_{b}, x_{f}^{\prime}, \tau_{+}\right)<V_{h}\left(x_{f}, x_{b}, \tau\right) .
$$

The following result shows that such an equilibrium with all borrowers - regardless of their credit quality or tech-savviness - suffering from open banking exists for a range of primitive parameters.

Proposition 4. There exists a nonzero measure set of primitive parameters (as characterized in the proof), so that

1. in the unique (nontrivial) equilibrium, (a) all tech-savvy high-type borrowers and a fraction of tech-savvy low-type borrowers sign up (i.e. $\sigma_{h}=1$ and $\sigma_{l} \in(0,1)$ ), and (b) all borrowers become worse off compared to the case before open banking; and

2. in the above equilibrium, compared to the case before open banking, the bank loses while the fintech gains, industry profit improves, and market efficiency improves as well (if a low-type borrower generates an efficiency loss whenever she gets a loan). 
For those borrowers who choose not to sign up, they are perceived to have a lower average credit quality than the whole population $\left(\tau_{-}<\tau\right)$ and so become worse off compared to the case before open banking. For those who choose to sign up, they are viewed more favorably $\left(\tau_{+}>\tau\right)$, but if the screening ability gap becomes sufficiently large, they can still suffer from open banking. Of course both $\tau_{+}$and $\tau_{-}$are endogenous in equilibrium, and Proposition 4 ensures that such parameter configuration exists so that open banking makes all borrowers worse off.

When both market segments are active, both lenders make a positive profit (the bank earns from the opt-out market segment and the fintech earns from the sign-up market segment), but the bank earns less than before. When high-type borrowers also suffer from open banking, similarly as in the case of mandatory sign-up, the screening ability gap $\Delta^{\prime}$ must be sufficiently larger than $\Delta$. This explains why the total industry profit must rise in this situation at the expense of borrowers, which is perhaps contrary to the original intention of open banking regulations.

\section{Open Banking: Privacy and Targeted Loans}

We so far have focused on sharing data on borrowers' credit quality. However, the data that modern financial institutions process are multidimensional, and contain information on other aspects of customer behavior as well. This section studies "privacy" concerns, i.e., some non-credit information that borrowers are reluctant to share with their lenders. Such extra information can be particularly valuable for fintech companies given their more advanced "big data" technology, but a certain type of "precision marketing" based on such information could potentially hurt customers. Exactly out of this consideration, and guided by the open-data philosophy mentioned in the introduction, many regulators around the world mandate consent from customers themselves when sharing their data.

We offer a tractable analysis of equilibrium open banking when non-credit privacy data sharing is intertwined with credit quality inference. We show that all borrowers could be worse off even if they control their own data (a similar result as we saw in the previous section); the endogenous credit quality inference, as the backbone of the lending market competition, implies the sign-up population is non-monotone in the degree of privacy concerns.

\subsection{Consumer "Preferences" for Fintech Loans}

Among many potential angles that one could take to explore "privacy," we focus on the information about consumer/borrower preferences. This category of information complements well the information on credit quality studied in Section 3 which could be viewed as the information on loan costs.

Taking the baseline model in Section 2, suppose now that each borrower is subject to a privacy event shock, so that with a probability $\xi>0$ the borrower can take out loans only from the fintech lender. This privacy event, simply called the $\xi$-event, is independent of the borrower's credit quality type. Before open banking, this privacy event is unobservable to both lenders. However, with open banking, this event will be revealed to the fintech lender perfectly for borrowers who sign up for 
open banking, so fintech lenders will be able to know exactly when borrowers are "locked in" to fintech loans. Albeit stark, our modeling of $\xi$-events is motivated by "event-based marketing," and captures the idea that open banking enables fintech lenders to perform "precision marketing" by combining the newly accessible borrower's banking transaction records with some other existing information (e.g., the borrower's social media data). ${ }^{24}$ Open banking hence helps fintech lenders invade the borrower's privacy.

In general, consumer privacy and precision marketing in our setting fall into two broad categories. The first is when some borrowers strongly prefer fintech loans. For instance, when a consumer shops on an e-commerce platform, she might have a strong preference for "immediacy" (i.e., buying a certain product immediately). If she needs to borrow but has no credit cards, in this case fintech lenders often dominate traditional banks by processing loan applications much faster. ${ }^{25}$ With open banking, the transaction records from the borrower's bank (which may contain important information, say, on the borrower's consumption habits), together with the borrower's digital footprint, often enable the fintech lender to better identify the event of demand immediacy.

The second category is when borrowers face a restricted set of available lenders in some circumstances. For example, a borrower could be ineligible for bank loans sometime (e.g., because she happens to be close to the bank's borrowing limit), or she travels abroad and needs an emergency loan in foreign currency (say for health insurances) unavailable from her bank. Open banking provides such information to fintech lenders so that they can then target the borrower more precisely.

We assume that these $\xi$-events are realized "ex post", after borrowers have made their sign-up decisions; this way, the belief updating with regard to the borrower's opt-in/opt-out decision is only on credit quality, just like in Section 3. Our previous real-world examples are chosen to highlight the idiosyncratic nature of these privacy events. In practice, customer borrowers often decide once and for all whether to opt in or opt out of open banking when they start using the fintech services; a case-by-case decision likely involves a prohibitively high attention cost. Even if one can swiftly opt out of open banking "without strings attached" as described in the Deloitte Insight survey in the introduction, borrowers are unlikely to know exactly what data will be useful for the fintech, without mentioning that it might be too late to opt out as they have consented to sharing their recent banking history.

Given that the borrowers in the $\xi$-event can borrow from the fintech only, they are similar to the "captured" consumers in Varian (1980). But our model offers some new economics due to the winner's curse embedded in the credit market competition. For instance, in contrast to the Varian model, we will show soon that the possibility of being captured does not always hurt a borrower,

\footnotetext{
${ }^{24}$ Precision marketing is a broader idea in retail business. Doug Shaddle, Director of Sales for UberMedia, once said that "the adoption of mobile technology is creating new data streams that can provide retailers with an unprecedented amount of information about who their shoppers are and how to bring them further into the fold, ... to deliver the right offer, at the right time, to the right customer." (See https://bwnews.pr/2FBXeA3.) Of course, broadly speaking, precision marketing could play a role for our study of credit information in Section 3 if the fintech, due to its superior technology, can classify borrowers into more categories after open banking and so tailor more personalized offers. It is an interesting direction for future research.

${ }^{25}$ See, for instance, Fuster, Plosser, Schnabl, and Vickery (2019) for evidence that fintechs are faster at processing loans in the context of housing mortgages.
} 
and also the fintech does not always earn a positive profit even with some captured borrowers. ${ }^{26}$

\subsection{Competition Equilibrium before Open Banking}

We first extend the baseline model in Section 2 to include the $\xi$-event and analyze the credit market competition before open banking. The resulting equilibrium serves as the benchmark for later analysis.

\subsubsection{The magnitude of $\xi$}

The equilibrium structure crucially depends on the magnitude of $\xi$, i.e., the probability that a borrower can borrow from the fintech only. When

$$
\xi \leq \phi(\bar{r}) \triangleq \frac{x_{b}}{\frac{\tau}{1-x_{f}} \bar{r}-\left(1-x_{b}\right)}<1
$$

the fintech lender (who has a weaker screening ability) still makes a zero profit, and the equilibrium structure is similar as in Proposition 1 (i.e., the baseline case of $\xi=0$ ). When $\xi>\phi(\bar{r})$, however, both lenders earn a positive profit with a different equilibrium structure. In fact, by simply charging the maximum interest rate $\bar{r}$ (upon seeing a good signal), the fintech gains from borrowers who pass both screenings and are in their $\xi$-events, but loses from serving borrowers who are rejected by the bank: ${ }^{27}$

$$
\underbrace{\xi \cdot p_{H H}\left[\mu_{H H}(\bar{r}+1)-1\right]}_{\text {profit from } \xi \text {-events with two good signals }}-\underbrace{p_{L H}}_{\text {winner's curse }}=p_{L H}\left(\frac{\xi}{\phi(\bar{r})}-1\right) .
$$

When $\xi$ exceeds the critical value in (18), the gain dominates and hence the fintech with a sufficient measure of captured borrowers earns a positive profit.

\subsubsection{Equilibrium characterization before open banking}

When (18) holds, the bank always makes an offer upon seeing a good signal, while the zero-profit fintech makes an offer with probability $m_{f}^{\xi}<1$, where we use the superscript " $\xi$ " to indicate the model with a possible $\xi$-event. The two lenders' indifference conditions are similar to those in the baseline:

$$
p_{H H}(\underbrace{(1-\xi) \bar{F}_{b}^{\xi}(r)}_{\text {win if beats bank }}+\underbrace{\xi}_{\text {win for sure }})\left[\mu_{H H}(r+1)-1\right]-p_{L H}=\underbrace{\pi_{f}^{\xi}=0}_{\text {fintech: zero profit }}
$$

\footnotetext{
${ }^{26}$ Also, with open banking our model is a variant of Varian (1980) where only one firm can identify its captured consumers and hence price discriminate accordingly. This scenario, which is quite natural in our context of credit market competition, is rarely considered in the literature on industrial organization.

${ }^{27}$ For the purpose of illustration, the borrower in the $\xi$-event is assumed to be screened by the bank (though never take a loan from it); this is without loss of generality because the fintech does not learn from the bank's screening result.
} 
and

$$
\underbrace{(1-\xi)}_{\text {shrunk market size }}\left\{p_{H H}\left(1-m_{f}^{\xi}+m_{f}^{\xi} \bar{F}_{f}^{\xi}(r)\right)\left[\mu_{H H}(r+1)-1\right]-p_{H L}\right\}=\underbrace{\pi_{b}^{\xi}>0}_{\text {bank: positive profit }} .
$$

When (18) does not hold, both lenders will make an offer for sure upon seeing a good signal, and so we will have $m_{f}^{\xi}=1$ and $\pi_{f}^{\xi}>0$ in the above two indifference conditions.

Recall $V_{i}(\tau)$ in (9) and (10); we omit the screening ability variables since they are kept constant in this section. The following proposition reports the details of the equilibrium.

Proposition 5. Before open banking, the equilibrium with possible privacy event can be characterized as follows;

1. When $\xi<\phi(\bar{r})$, the fintech makes a zero profit $\pi_{f}^{\xi}=0$ while the bank makes a profit $\pi_{b}^{\xi}=$ $(1-\xi) \frac{x_{b}-x_{f}}{1+\tau}>0$. The fintech adopts the same pricing strategy as in Proposition 1 with $m_{f}^{\xi}=1-\phi(\bar{r})$, and the bank's pricing strategy is characterized by $\bar{F}_{b}^{\xi}(r)=\frac{\phi(r)-\xi}{1-\xi}$ with $m_{b}^{\xi}=1$. The borrower surpluses are:

$$
\begin{aligned}
V_{h}^{\xi}(\tau) & =V_{h}(\tau) \\
V_{l}^{\xi}(\tau) & =V_{l}(\tau)-\xi \delta\left(1-x_{b}\right)\left(x_{f}+\left(1-x_{f}\right) \phi(\bar{r})\right) .
\end{aligned}
$$

2. When $\xi=\phi(\bar{r})$, there exists a continuum of equilibria indexed by $m_{f}^{\xi} \in[1-\phi(\bar{r}), 1]$, which is the fintech's loan offer probability to a borrower with a good signal. Everything else is identical to case (1), except for the low-type surplus which is given in Appendix A.9.

3. When $\xi>\phi(\bar{r})$, both lenders make positive profits. Upon seeing a good signal both lenders always make an offer (i.e., $m_{f}^{\xi}=m_{b}^{\xi}=1$ ), with interest rate distributions $\bar{F}_{b}^{\xi}(r)=\frac{\xi}{1-\xi}$. $\frac{\phi(r)-\phi(\bar{r})}{\phi(\bar{r})}$ and $\bar{F}_{f}^{\xi}(r)=\frac{\xi}{\phi(\bar{r})} \cdot \phi(r)$. The borrower surpluses are

$$
\begin{aligned}
V_{h}^{\xi}(\tau) & =(1-\xi)^{2}\left[\bar{r}-\frac{\left(1-x_{b}\right)\left(1-x_{f}\right)}{\tau}\right]<V_{h}(\tau), \\
V_{l}^{\xi} & =\delta\left[(1-\xi)\left(1-x_{b} x_{f}\right)+\xi\left(1-x_{f}\right)\right] .
\end{aligned}
$$

The third case of a relatively large $\xi>\phi(\bar{r})$ is similar to the Varian-type model (with asymmetric sizes of captured consumers across firms). Thanks to its relatively large base of (potentially) captured borrowers, the fintech-despite its weaker credit screening ability - always extends loan offers upon seeing a good signal and makes a positive profit. The larger the $\xi$, the more the captured borrowers, and the higher interest rates from both lenders in the sense of FOSD.

The first case of a relatively small $\xi<\phi(\bar{r})$ is more "surprising." We find that the fintech with relatively few captured borrowers takes a pricing strategy that is independent of $\xi$-more precisely, it is the same as in the baseline $\xi=0$. The bank, in contrast, prices more aggressively. Why? As typical in a setting with a mixed-strategy equilibrium, the bank's pricing strategy is determined by 
the fintech's zero-profit condition (20). But the zero-profit condition implies that the fintech must lose from non-captured borrowers in equilibrium. As a result, the bank bids more aggressively (and earns less), so much so that high-type borrowers lose nothing from the presence of potential $\xi$-event; see Eq. (22). (This result differs from the case of large $\xi$ just discussed above, or more generally, the Varian-type model.) On the other hand, because the potential $\xi$-event prevents borrowers from taking bank loans, this hurts low-type borrowers who only care about the chance of receiving a loan. ${ }^{28}$

Finally, in the knife-edge case (2), when $\xi=\phi(\bar{r})$ there exists a continuum of equilibria indexed by $m_{f}^{\xi} \in[1-\phi(\bar{r}), 1]$, the fintech's probability of making an offer upon seeing a good signal. This explains why low-type borrowers who care only about loan probabilities are affected by the fintech's policy. In this continuum of equilibria, $m_{f}^{\xi}=1-\phi(\bar{r})$ corresponds to case (1) with $\xi<\phi(\bar{r})$, while $m_{f}^{\xi}=1$ corresponds to case $(3)$ with $\xi>\phi(\bar{r})$. This continuum of equilibria plays a role when we analyze the model with voluntary sign-up.

\subsection{Equilibrium Open Banking with Targeted Loans}

We first solve the mandatory sign-up case to highlight the type-dependent incentives to opt in, and then characterize the equilibrium when sign-up is voluntary. To highlight the new role of open banking in this section, we assume that the fintech lender's screening ability on credit type remains unchanged (i.e., $x_{f}^{\prime}=x_{f}$ ) after open banking. ${ }^{29}$ The fintech gains from open banking by taking advantage of the borrowers' data to extend targeted loans in the $\xi$-event.

\subsubsection{Mandatory sign-up}

Suppose that borrowers are mandated to sign up for open banking. To borrowers in their $\xi$-events, the fintech charges the monopolistic rate $\bar{r}$ whenever it sees a good signal. For borrowers in their non- $\xi$-events, lenders compete as in Proposition 1, leading a zero profit for the fintech. The fintech's expected profit hence is:

$$
\pi_{f}^{\xi, O B}=\xi \cdot(\underbrace{\theta \bar{r}}_{\text {profit from high-type }}-\underbrace{(1-\theta)\left(1-x_{f}\right)}_{\text {loss from low-type given } H \text { signal }})=\xi \cdot \frac{\tau \bar{r}-\left(1-x_{f}\right)}{1+\tau}>0 .
$$

Superscript " $\xi, O B$ " indicates the $\xi$-event model under open banking.) For borrower surplus, in the $\xi$-event, a high-type borrower is charged $\bar{r}$ (hence no rent left), while a low-type borrower receives a loan given a good signal from the fintech (which occurs with probability $1-x_{f}$ ). Therefore with

\footnotetext{
${ }^{28}$ The potential $\xi$-event hurts the low-type borrower, relative to the baseline model, only in the following scenario. The borrower receives a good signal from the bank (which occurs with prob. $1-x_{b}$ ) but the fintech does not make any loan (which occurs with probability $x_{f}+\left(1-x_{f}\right) \phi(\bar{r})$, the fintech either receives a bad signal, or a good signal but does not lend). This explains $\xi\left(1-x_{b}\right)\left(x_{f}+\left(1-x_{f}\right) \phi(\bar{r})\right)$ in Eq. $(23)$.

${ }^{29}$ For this reason, we have ignored the screening ability variables in the borrower surplus function in this section.
} 
open banking and mandatory sign-up, the type-dependent borrower surpluses are:

$$
\begin{aligned}
V_{h}^{\xi, O B}(\tau) & =(1-\xi) V_{h}(\tau), \\
V_{l}^{\xi, O B}(\tau) & =(1-\xi) V_{l}(\tau)+\delta \xi\left(1-x_{f}\right),
\end{aligned}
$$

where $V_{i}(\tau)$ are in $(9)$ and $(10)$.

By comparing them to Proposition 5, we have the next proposition on the impacts of open banking (with mandatory sign-up):

Proposition 6. Compared to the regime before open banking,

1. there exists $\hat{\xi} \in(\phi(\bar{r}), 1)$ such that high-type borrowers suffer from open banking with mandatory sign-up if and only if $\xi \leq \hat{\xi}$, while low-type borrowers suffer if and only if $\xi>\phi(\bar{r})$. Therefore both types of borrower strictly suffer when $\xi \in(\phi(\bar{r}), \hat{\xi})$; and

2. open banking with mandatory sign-up helps the fintech but (weakly) harms the bank.

The fintech benefits from open banking, as it now can price discriminate and offer targeted loans to exploit the borrowers in their $\xi$-events. The bank strictly suffers when $\xi>\phi(\bar{r})$, because in that case after open banking, the fintech will compete more aggressively for non-- $\xi$-event borrowers. (When $\xi \leq \phi(\bar{r})$, the fintech adopts the same pricing strategy before and after open banking, and that is why open banking has no impact on the bank.)

Open banking has an intriguing type-dependent impact on borrower surplus, which drives our analysis of the voluntary sign-up equilibrium in the next section. When $\xi<\phi(\bar{r})$ so that the fintech lender still earns zero profit before open banking, the high type suffer from open banking which facilitates the fintech to target their $\xi$-events. In comparison, the low type benefit since they now receive an offer for sure in the $\xi$-event if the signal is good (but before open banking in the same event, the fintech might not make offers as $m_{f}^{\xi}<1$ ).

When $\xi>\phi(\bar{r})$ so that the privacy concern is relatively large, the result concerning the lowtype surplus is reversed. Thanks to a sufficiently large number of captured borrowers, before open banking the fintech lender makes a strictly positive profit and always offers a loan upon seeing a good signal. However, after open banking, the fintech can identify captured borrowers perfectly, and as a result it scales back in non-- $\xi$-events $\left(m_{f}^{\xi, O B}<1\right.$ so it randomly drops out without making offers). Low-type borrowers thus prefer opting out of open banking.

For high-type borrowers, they could gain strictly from open banking when $\xi>\hat{\xi}$; this is again in contrast to being harmed by open banking when $\xi$ is small. To see this result, consider the limiting case of $\xi \rightarrow 1$. Before open banking, knowing that the fintech will be the de facto monopolist, both lenders charge interest rates that converge to $\bar{r}$. After open banking, the bank-knowing that the fintech can identify captured borrowers perfectly - offers an interest rate independent of $\xi$. This implies that the high-type benefit from open banking.

Proposition 6 delivers a result that is parallel to Proposition 3 in Section 3 on credit quality data sharing: It is possible that both types of borrower strictly suffer from open banking with mandatory 
sign-up. Just like in Section 3, this perverse welfare effect can hold even when borrowers voluntarily choose to share their "privacy" data, as we show now.

\subsubsection{Voluntary sign-up}

Now we study the case with voluntary sign-up. As in Section 3, let $\rho$ be the measure of non-techsavvy borrowers with an infinite sign-up cost, which is independent of both credit quality type as well as of the privacy event.

Recall that the fraction of the tech-savvy type- $i$ borrowers who sign up for open banking is denoted by $\sigma_{i} \in[0,1]$, and the updated priors of credit quality in the two market segments are respectively $\tau_{+}$for the opt-in market and $\tau_{-}$for the opt-out market as defined in (12). In this section we further assume that $\rho$ is sufficiently large:

$$
\rho \tau \bar{r}>1-x_{f} .
$$

The condition says even if $\sigma_{h}=1$ (all high-type tech-savvy borrowers opt in) while $\sigma_{l}=0$ (all low-type tech-savvy borrowers opt out), lenders still serve both segments thanks to a sufficiently favorable updated opt-out prior $\tau_{-}$, in light of condition (1).

Crucially, lender competition in the opt-out segment resembles that in Proposition 5 before open banking, but the threshold value for $\xi$ - which is $\phi\left(\bar{r} ; \tau_{-}\right)$- is endogenous and depends on the updated opt-out prior $\tau_{-}$. For this reason, we write the dependence of $\tau_{-}$of $\phi\left(\bar{r} ; \tau_{-}\right)$explicitly; $\phi\left(\bar{r} ; \tau_{-}\right)$is decreasing in $\tau_{-}$. The following proposition fully characterizes the unique equilibrium that arises, when we vary $\xi$.

Proposition 7. With the potential privacy event and voluntary sign-up for open banking, we have

1. when $\xi<\phi(\bar{r} ; \tau)$, there exists a unique equilibrium where no borrowers sign up, i.e., $\sigma_{h}=$ $\sigma_{l}=0$

2. when $\phi(\bar{r} ; \tau)<\xi<\phi(\bar{r} ; \rho \tau)$, there exists a unique equilibrium where $\sigma_{h}>\sigma_{l}>0$, so that $\tau_{-}=\tau \frac{1-(1-\rho) \sigma_{h}}{1-(1-\rho) \sigma_{l}}$ satisfies $\xi=\phi\left(\bar{r} ; \tau_{-}\right)$; and

3. when $\xi>\phi(\bar{r} ; \rho \tau)$, there exists a unique equilibrium where only high-type borrowers sign up, i.e., $\sigma_{h}=1$ while $\sigma_{l}=0$.

The case of small $\xi<\phi(\bar{r} ; \tau)$. When $\xi$ is sufficiently small, the unique equilibrium is that nobody signs up for open banking. This explains why the average credit quality in the opt-out segment is $\tau_{-}=\tau$ (i.e., the prior), and the lender competition in the opt-out segment falls into case (1) of Proposition 5.

The intuition is as follows. As we have pointed out in Proposition 6, fixing the average credit quality, the low-type is more willing to opt in than the high-type. The high-type suffers from open banking due to fintech exploitation of the privacy event, while the interest rate-insensitive low-type on the contrary benefits from a greater chance of receiving a loan. It is in sharp contrast to Lemma 
2 which concerns sharing credit quality data in Section 3. There, the high type naturally prefers a more precise screening technology (relative to the low type); while here, signing up for open banking means exposing the high type to exploitation by the fintech charging a monopolistic rate (something that the low type do not care).

This gives rise to a "stigma" effect - akin to the one in the context of Fed's discount window (e.g., Armantier, Ghysels, Sarkar, and Shrader, 2015) - of associating signing up with low credit quality. Then the low type would not sign up either because doing so would reveal their credit quality type. Consequently, the only equilibrium is nobody signing up.

The case of large $\xi>\phi(\bar{r} ; \rho \tau)$. When $\xi$ is sufficiently large, the unique equilibrium is that only high-type (tech-savvy) borrowers sign up for open banking. This explains the equilibrium updated opt-out prior $\tau_{-}=\rho \tau$, and the lender competition in the opt-out segment falls into case (3) of Proposition 5.

Again the endogenous credit quality inference is crucial, because the equilibrium is driven by low-type borrowers always preferring to opt out. Eq. (25) in Proposition 5 shows that their opt-out surplus $V_{l}^{\xi}$ is independent of $\tau_{-}$; in fact, $V_{l}^{\xi}$ achieves its upper bound because both the fintech (with a sufficiently large measure of captured borrowers) and the bank always make an offer upon good signals. Opting in open banking exposes the low type to the risk of the fintech (as the weaker lender) not to make loans in their non- $\xi$-events. No low-type tech-savvy borrower will opt in, and then the equilibrium inference is that whoever signs up must be a high-type borrower. We show that this favorable credit quality inference is sufficient to convince the high type to always sign up for open banking in equilibrium, despite the exposure of their privacy events.

The case of intermediate $\xi \in(\phi(\bar{r} ; \tau), \phi(\bar{r} ; \rho \tau))$. When $\xi$ falls in the intermediate range, the unique equilibrium takes the form of the knife-edge case (2) in Proposition 5. There, the equilibrium sign-up populations of both (tech-savvy) types endogenously ensure that $\xi=\phi\left(\bar{r} ; \tau_{-}\right)$, and we pin down the fintech's loan offering probability $m_{f}^{\xi}$ from the two borrower's indifference conditions.

\subsection{Impact of Open Banking and Voluntary Sign-up}

Our discussion is based on the following proposition. We first define the sign-up population to be

$$
p(\xi) \equiv(1-\rho)\left[\theta \sigma_{h}(\xi)+(1-\theta) \sigma_{l}(\xi)\right]
$$

Proposition 8. The open banking sign-up population $p(\xi)$ is single peaked at $\tilde{\xi} \in(\phi(\bar{r} ; \tau), \phi(\bar{r} ; \rho \tau))$. For all $\xi \in[\phi(\bar{r} ; \tau), \tilde{\xi}]$, relative to the case before open banking, all borrowers are strictly worse off; the fintech gains while the bank loses; and the financial industry gains under conditions given in the proof. 


\section{Figure 2: Equilibrium Open Banking Sign-up Population and Borrower Surplus}
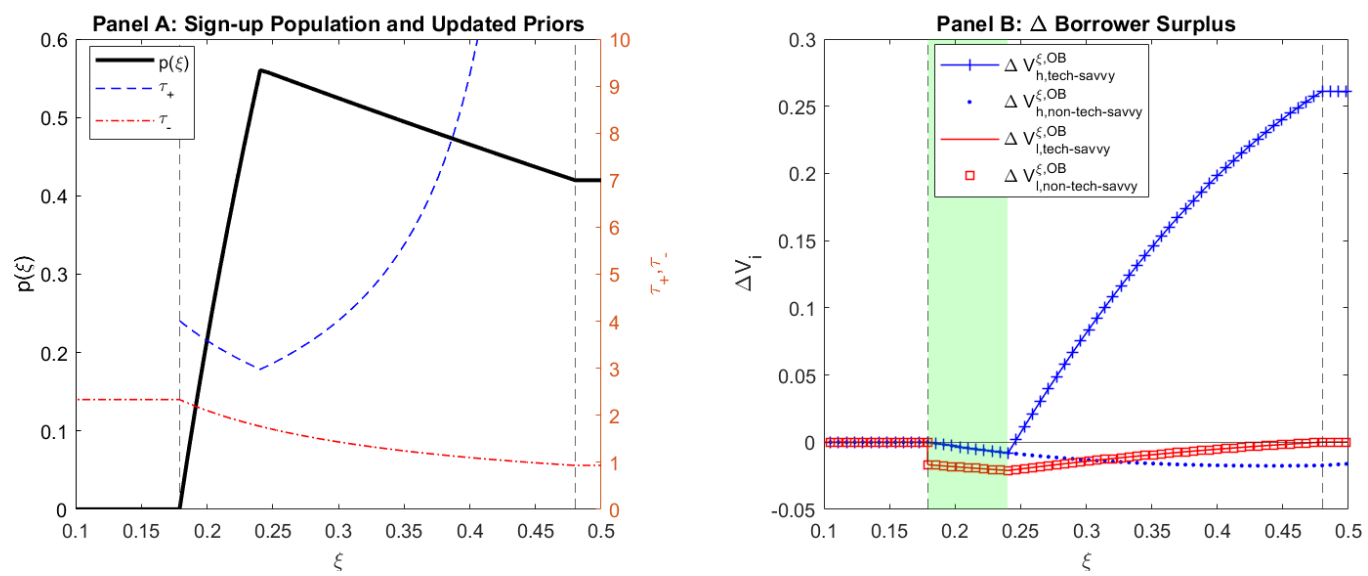

Panel A plots the open banking sign-up population $p(\xi)$ as a function of $\xi$ (left scale); the updated opt-in and opt-out priors $\tau_{+}$and $\tau_{-}$(right scale). The updated prior $\tau_{+}$increases with $\xi$ and diverges to $\infty$ as $\xi \rightarrow \phi(\bar{r} ; \rho \tau)$; therefore we cap it at 10. Panel B plots borrower surpluses as a function of $\xi$; the solid blue lines with crosses (dots) are surplus for the (non-) tech-savvy high-type borrowers, while solid red lines (squares) are surplus for the (non-) tech-savvy low-type borrowers. In the figure, $\phi(\bar{r} ; \tau)=0.18$ and $\tilde{\xi}=0.24$. Parameter values are $\bar{r}=1, x_{b}=0.8, x_{f}=0.5, \delta=0.5, \rho=0.4$, and $\theta=0.7$.

\subsubsection{Sign-up population and privacy concerns}

Panel A in Figure 2 illustrates the total sign-up population and the updated priors in equilibrium, as a function of $\xi$. When $\xi$ increases, initially nobody signs up, $p(\xi)=0$, with the updated opt-out prior $\tau_{-}$staying at the prior $\tau$. Both types of tech-savvy borrowers start to sign up once $\xi$ exceeds $\phi(\bar{r} ; \tau)$, which takes a value of 0.18 in our numerical example. The updated opt-out prior $\tau_{-}$goes down afterwards, while the updated opt-in prior $\tau_{+}$in the opt-in segment always sits above the prior $\tau$. The total sign-up population as shown peaks at $\tilde{\xi}=0.24$ then goes down afterward; this is because $\sigma_{h}=1$ while $\sigma_{l}$ decreases for $\xi>\tilde{\xi}$, explaining the pattern of updated priors in both segments. When $\xi>\phi(\bar{r} ; \rho \tau)=0.48$, as shown in Panel A the sign-up population $p(\xi)$ remains at $(1-\rho) \theta>0$, which is the measure of tech-savvy high-type borrowers.

Our analysis hence generates a surprising comparative static result on the non-monotonic relation between the equilibrium sign-up population $p(\xi)$ and $\xi$. A casual thinking might suggest that $p(\xi)$ decreases with $\xi$, as $\xi$ captures the borrowers' privacy concern against data sharing. We show that this casual thinking captures some economics, but only partially. In the scenario of small $\xi$, open banking allows fintech lenders to target high-type borrowers who are concerned about unfair pricing, and in fact this stigma effect goes a long way to prevent everybody from signing up for open banking, as discussed after Proposition 7. However, when the magnitude of the privacy concern $\xi$ is large, the opt-out incentive of low-type borrowers dominates the equilibrium credit quality inference, and eventually all tech-savvy high-type borrowers sign up for open banking in equilibrium.

Our paper hence sheds some light on the economics behind the slow adoption of the open 
banking over time. Since the creation of the Open Banking Implementation Entity (OBIE) by the Competition and Markets Authority (CMA) in the UK in 2016, the industry has witnessed little enthusiasm from consumers. ${ }^{30}$ This lukewarm reception is often attributed to potential securityrelated privacy concerns caused by data sharing. Our analysis on the interaction between privacy and credit quality calls for a more careful examination of this conventional wisdom.

Taking a slightly different interpretation, our model also suggests that the adoption of open banking might grow as the business models of the fintech lenders under consideration improves. Note, the parameter $\xi$ measures the fraction of captured borrowers that can be potentially identified and targeted by fintech lenders. Therefore, another useful way to think about the magnitude of $\xi$ as the proxy for the development of fintech businesses. The case of small $\xi$ corresponds to an underdeveloped "challenger" fintech lender whose business model is in its relative early stage, lacking a clearly defined target market. In these small- $\xi$ markets, nobody signs up for open banking in equilibrium. Over time, our model predicts the sign-up population will grow, once fintech lenders have established their niche markets with more and more captured customers - e.g., young Ivy League graduates who live in major metropolitan cities-and eventually become profitable after launching certain successful differentiated products.

\subsubsection{Welfare: the perverse effect of open banking}

Proposition 8 shows that open banking could make all borrowers worse off even though they control their own data, and at the same time lead to a higher industry profit. This result follows irrespective of whether the data sharing concerns credit quality information as in Section 3, or some privacy information that facilitates making exploitative loans as studied here.

To understand the result regarding borrower surpluses, ${ }^{31}$ the perverse effect of open banking emerges in the shaded green area as illustrated in Panel B in Figure 2. Consider $\xi^{\prime}=\phi(\bar{r} ; \tau)+\epsilon$; we already know from Proposition 6 that both types of borrowers suffer when sign-up is mandatory. The intuition for why the low type get worse off due to open banking is similar to Proposition 6 and quite straightforward. Before open banking, the fintech with a sufficiently large number of captured borrowers lends aggressively $\left(m_{f}^{\xi}=1\right)$ upon seeing a good signal, benefiting the low type. With open banking and voluntary sign-ups, lender competition in the opt-out segment follows case (2) in Proposition 5; there, some endogenous $m_{f}^{\xi}<1$ emerges to ensure the indifference condition of borrowers regarding their sign-up decisions. This hurts the low-type borrowers, whose equilibrium value is the same regardless of whether they are tech savvy or not, opt-in or opt-out (Panel B in Figure 2).

Now we turn to high-type borrowers. For the tech-savvy high-type borrowers who choose to

\footnotetext{
${ }^{30}$ For instance, see Warwick-Ching (2019), among others. The ongoing COVID-19 pandemic, which has forced consumers and financial institutions alike to recognize the essential nature of digital interactions, offers a great boost to the adoption of open banking. According to OBIE, over 2 million UK bank customers have connected their accounts to trusted third parties by the end of September 2020, up from 1 million in January 2020. See https://bit.1y/3kTvbvg.

${ }^{31}$ The intuition of the lender profit result is similar to the one given right after Proposition 6.
} 
sign up, they suffer from the fintech's exploitative targeted loans facilitated by open banking, as

shown in Proposition 6 for $\xi^{\prime}=\phi(\bar{r} ; \tau)+\epsilon<\tilde{\xi}$. Clearly, those who choose to opt out must be worse off as well thanks to the indifference equilibrium condition between opt-in and opt-out, and the mechanism is the endogenous credit quality inference. To see this, the updated opt-out prior, i.e., $\tau_{-}\left(\xi^{\prime}\right)$ that solves $\xi^{\prime}=\phi\left(\bar{r} ; \tau_{-}\left(\xi^{\prime}\right)\right)$, must be below the prior $\tau$ (as shown in Panel A in Figure $8)$; this is because for the fintech to be break-even, we must have a lower updated prior for credit quality $\tau_{-}$to compensate for a larger measure of captured borrowers. But a lower $\tau_{-}$implies that high-type borrowers in the opt-out segment receive worse treatment from lenders, even if they choose not to sign up for open banking.

\section{Conclusion}

As the volume of data created by the digital world continues to grow, customer data has evolved into a defining force in every business of banking including small business credit, consumption loans, and retail services. Open banking regulation that requires banks to share their existing customers' data with third parties - notably, fintech lenders - at customers' requests can be viewed as an integral part of the broader "open economy" initiative, in which the data should be open to outside third parties at the consent of customers who generate them.

We offer the first theoretical study on the consequence of letting borrowers control their own data in an otherwise classic credit market competition between an incumbent traditional bank and a challenger fintech lender. Two kinds of data sharing by borrowers are explored: one concerns their creditworthiness (i.e., information on lending cost), and the other their choice "privacy" (i.e., information on customer preferences).

Although our results generally support the premise that open banking favors challenger fintechs, we highlight that the voluntary nature of data sharing is not sufficient to protect borrowers' welfare. In both scenarios, we show the general existence of scenarios in which all borrowers are strictly worse off (while the whole financial industry becomes more profitable), even for those who opt out of open banking. This perverse effect is largely driven by the credit quality inference from borrower's "signup" decisions, which is rooted in adverse selection as the backbone of credit market competition. Broadly, this effect is consistent with the information externality caused by consumer decisions, which poses a long-standing challenge to regulations on consumer protection in modern financial industry.

There are a few other important issues on open banking that we leave for future research. First, traditional banks operate not only in the lending market but also in the deposit and payment service market. Open banking affects their competition with fintech challengers in the latter market as well, leading to another potential perverse effect on consumers. For instance, as the transaction account service provides the most valuable data for traditional banks, data sharing required by open banking may dampen their incentives to compete in that market. Second, from a long-term perspective, should successful fintech giants also be required to share data back with traditional 
banks? Third, we take open banking regulation as given; but is it better than the market mechanism where traditional banks act as data brokers and sell their data (upon customer consent) to fintechs? 


\section{References}

Abadi, Joseph, and Markus Brunnermeier, 2019, Blockchain economics, Available at SSRN.

Acquisti, Alessandro, Curtis Taylor, and Liad Wagman, 2016, The economics of privacy, Journal of Economic Literature 54, 442-92.

Ali, S Nageeb, Greg Lewis, and Shoshana Vasserman, 2020, Voluntary disclosure and personalized pricing, in Proceedings of the 21st ACM Conference on Economics and Computation pp. 537-538.

Aridor, Guy, Yeon-Koo Che, and Tobias Salz, 2020, The economic consequences of data privacy regulation: Empirical evidence from gdpr, Discussion paper National Bureau of Economic Research.

Armantier, Olivier, Eric Ghysels, Asani Sarkar, and Jeffrey Shrader, 2015, Discount window stigma during the 2007-2008 financial crisis, Journal of Financial Economics 118, 317-335.

Banerjee, Priyodorshi, 2005, Common value auctions with asymmetric bidder information, Economics Letters 88, 47-53.

Berg, Tobias, Valentin Burg, Ana Gombović, and Manju Puri, 2020, On the rise of fintechs: Credit scoring using digital footprints, The Review of Financial Studies 33, 2845-2897.

Bergemann, Dirk, and Alessandro Bonatti, 2019, Markets for information: An introduction, Annual Review of Economics 11, 85-107.

Biais, B., C. BisiÃšre, M. Bouvard, and C. Casamatta, 2019, The blockchain folk theorem, The Review of Financial Studies 32, 1662-1715.

Bouckaert, Jan, and Hans Degryse, 2006, Entry and strategic information display in credit markets, The Economic Journal 116, 702-720.

Broecker, Thorsten, 1990, Credit-worthiness tests and interbank competition, Econometrica: Journal of the Econometric Society pp. 429-452.

Buchak, Greg, Gregor Matvos, Tomasz Piskorski, and Amit Seru, 2018, Fintech, regulatory arbitrage, and the rise of shadow banks, Journal of Financial Economics 130, 453-483.

Dell'Ariccia, Giovanni, and Robert Marquez, 2004, Information and bank credit allocation, Journal of Financial Economics 72, 185-214.

— 2006, Lending booms and lending standards, The Journal of Finance 61, 2511-2546.

Di Maggio, Marco, and Vincent Yao, 2020, Fintech borrowers: Lax-screening or cream-skimming?, Available at SSRN 322495\%.

Engelbrecht-Wiggans, Richard, Paul R Milgrom, and Robert J Weber, 1983, Competitive bidding and proprietary information, Journal of Mathematical Economics 11, 161-169.

Fuster, Andreas, Matthew Plosser, Philipp Schnabl, and James Vickery, 2019, The role of technology in mortgage lending, The Review of Financial Studies 32, 1854-1899.

Hausch, Donald B, 1987, An asymmetric common-value auction model, The RAND Journal of Economics pp. 611-621. 
Hauswald, Robert, and Robert Marquez, 2003, Information technology and financial services competition, The Review of Financial Studies 16, 921-948.

He, Zhiguo, and Lin William Cong, 2019, Blockchain disruption and smart contracts, The Review of Financial Studies 32, 1754-1797.

Ichihashi, Shota, 2020, Online privacy and information disclosure by consumers, American Economic Review 110, 569-95.

Jones, Charles I., and Christopher Tonetti, 2020, Nonrivalry and the economics of data, American Economic Review 110, 2819-58.

Kagel, John H, and Dan Levin, 1999, Common value auctions with insider information, Econometrica $67,1219-1238$.

Liu, Zhuang, Michael Sockin, and Wei Xiong, 2020, Data privacy and temptation, Discussion paper National Bureau of Economic Research.

Marquez, Robert, 2002, Competition, adverse selection, and information dispersion in the banking industry, The Review of Financial Studies 15, 901-926.

Milgrom, Paul, and Robert J Weber, 1982, The value of information in a sealed-bid auction, Journal of Mathematical Economics 10, 105-114.

Pagano, Marco, and Tullio Jappelli, 1993, Information sharing in credit markets, The Journal of Finance 48, 1693-1718.

Parlour, Christine A, Uday Rajan, and Haoxiang Zhu, 2020, When fintech competes for payment flows, Available at SSRN.

Rajan, Raghuram G, 1992, Insiders and outsiders: The choice between informed and arm's-length debt, The Journal of finance 47, 1367-1400.

Sharpe, Steven A, 1990, Asymmetric information, bank lending, and implicit contracts: A stylized model of customer relationships, The Journal of Finance 45, 1069-1087.

Srinivas, Val, Jan-Thomas Schoeps, and Aarushi Jain, 2019, Executing the open banking strategy in the united states, Deloitte Insights.

Stole, Lars A, 2007, Price discrimination and competition, Handbook of Industrial Organization 3, $2221-2299$.

Tang, Huan, 2019, Peer-to-peer lenders versus banks: substitutes or complements?, The Review of Financial Studies 32, 1900-1938.

Thakor, Anjan V, 1996, Capital requirements, monetary policy, and aggregate bank lending: theory and empirical evidence, The Journal of Finance 51, 279-324.

Tirole, Jean, 2010, The theory of corporate finance (Princeton University Press).

Varian, Hal R, 1980, A model of sales, The American Economic Review 70, 651-659.

Vives, Xavier, 2019, Digital disruption in banking, Annual Review of Financial Economics 11, $243-272$. 
Von Thadden, Ernst-Ludwig, 2004, Asymmetric information, bank lending and implicit contracts: the winner's curse, Finance Research Letters 1, 11-23.

Warwick-Ching, Lucy, 2019, Open banking: the quiet digital revolution one year on, Financial Times.

\section{A Appendix A}

\section{A.1 Notation Summary}

Table 1: Notation Summary

\begin{tabular}{|c|c|c|}
\hline Notation & Definition and Meaning & Characterization \\
\hline$\theta$ & Probability of high-type & \\
\hline$\tau$ & Likelihood ratio of high-type & $\tau=\frac{\theta}{1-\theta}$ \\
\hline$\rho$ & Proportion of non-tech-savvy borrowers & \\
\hline$\mu_{i}, i \in\{h, l\}$ & Probability that a high/low-type repays & $\mu_{h}=1$ \\
\hline$\delta_{i}, i \in\{h, l\}$ & Borrower's private benefit of receiving a loan & $\delta_{h}=0, \delta_{l}=\delta>0$ \\
\hline$V_{i}\left(x_{w}, x_{s}, \tau\right)$ & Borrower $i$ 's surplus & \\
\hline$j \in\{b, f, s, w\}$ & Lender: traditional bank, or fintech; strong, or weak & \\
\hline$S_{j} \in\{H, L\}$ & Signal of lender $j$, is $H$ or $L$ & \\
\hline$x_{j}$ & Screening ability of lender $j$ in "bad news" structure & $\mathbb{P}\left(S_{j}=L \mid l\right)=x_{j}$ \\
\hline$p_{H H}, p_{H L}, p_{L H}, p_{L L}$ & Probabilities of lender signals & \\
\hline$\mu_{H H}, \mu_{H L}, \mu_{L H}, \mu_{L L}$ & Probabilities of repayment for borrowers with given signals & \\
\hline $\bar{r}$ & Upper bound of net interest rate (exogenous) & \\
\hline$\underline{r}$ & Lower bound of net interest rate & \\
\hline$m_{j}$ & Probability that lender $j$ grants a loan given $S_{j}=H$ & \\
\hline$r_{j}$ & Net interest rate offered by lender $j$ & \\
\hline$F_{j}(r) ; \bar{F}_{j}(r)$ & $\mathrm{CDF}$ of $r_{j} ;$ survival function of $F_{j}(r)$ & $\bar{F}_{j}(r)=1-F_{j}(r)$ \\
\hline$\lambda_{j}$ & The mass point of $F_{j}(r)$ at $\bar{r}$ & $\lambda_{j}=\lim _{r \uparrow \bar{r}} \bar{F}_{j}(r)$ \\
\hline$\pi_{j}$ & Lender $j$ 's profit & \\
\hline$\phi(r)$ & & $\mathrm{Eq}(6)$ \\
\hline$\Delta$ & Gap of screening ability & $\Delta=x_{s}-x_{w}$ \\
\hline$x_{f}^{\prime}$ & Screening ability of fintech after open banking in Section 3 & \\
\hline$\sigma_{i}, i \in\{h, l\}$ & Proportion of type $i$ tech-savvy borrowers who opt in & \\
\hline$\tau_{+}, \tau_{-}$ & Updated prior of borrowers who opt in $(+)$, and who opt out $(-)$ & \\
\hline$\xi$ & Probability of privacy event & \\
\hline$p(\xi)$ & Population of opt-in borrowers in Section 4 & \\
\hline
\end{tabular}

\section{A.2 Proof of Lemma 1}

Proof. Suppose first that $\pi_{s}, \pi_{w}>0$ in equilibrium. Then both lenders make an offer for sure upon seeing a good signal (i.e. $m_{s}=m_{w}=1$ ). From the two lenders' indifference conditions, we can 
see that as $r \uparrow \bar{r}$, at least one of $\bar{F}_{s}(r)$ and $\bar{F}_{w}(r)$ will be zero since it is impossible that both distributions have a mass point at $r=\bar{r}$. Thus, at least one of the lenders will make a negative profit, which is a contradiction.

Suppose then $\pi_{w} \geq \pi_{s}=0$. Then at $r=\underline{r}$, we must have $\bar{F}_{w}(r)=\bar{F}_{s}(r)=1$, and so we need $p_{L H} \leq p_{H L}$ to make both indifference conditions hold. But as we pointed out before this cannot be true given $x_{s}>x_{w}$. Therefore, the only remaining possibility is that $\pi_{s}>\pi_{w}=0$.

\section{A.3 Proof of Proposition 1}

Proof. We have known the strong lender's distribution is $\bar{F}_{s}(r)=\phi(r)$. From $\bar{F}_{s}(\underline{r})=1$, we solve $\underline{r}=\left(1-x_{w}\right) / \tau$, which is less than $\bar{r}$ given condition (1). The size of $F_{s}$ 's mass point is $\lambda_{s}=\phi(\bar{r})$, which is less than 1 given condition (1). Letting $r=\underline{r}$ in (3) yields $\pi_{s}=p_{L H}-p_{H L}=(1-\theta) \Delta=\frac{\Delta}{1+\tau}$, and letting $r=\bar{r}$ in (3) yields $1-m_{w}=\phi(\bar{r})$. Finally, $\bar{F}_{w}(r)$ is solved from (3).

\section{A.4 Proof of Corollary 1}

Proof. (i) Given $\pi_{s}=\frac{\Delta}{1+\tau}$, the result concerning profit is obvious.

(ii) For any given $r \in[\underline{r}, \bar{r}]$, it is easy to see that $\phi(r)$ defined in (6) increases in $x_{s}$, decreases in $x_{w}$, and decreases in $\tau$. So the claims follow immediately on the strong lender's interest rate distribution and the weak lender's probability of making an offer upon seeing a good signal. To see the result concerning the weak lender's interest rate distribution, notice that the derivative of

$$
\bar{F}_{w}(r)=\frac{x_{s}\left(1-x_{w}\right)}{\tau \bar{r}-\left(1-x_{w}\right)} \frac{\bar{r}-r}{r-\frac{\left(1-x_{s}\right)\left(1-x_{w}\right)}{\tau}}
$$

with respect to $x_{s}$ is proportional to

$$
\tau r-\left(1-x_{w}\right) \geq 0
$$

where the inequality is because $\underline{r}=\left(1-x_{w}\right) / \tau$. It is easy to see that $\bar{F}_{w}(r)$ decreases in both $x_{w}$ (as the numerator decreases in $x_{w}$ and the denominator increases in $x_{w}$ ) and $\tau$ (as the denominator increases in $\tau$ ).

\section{A.5 Proof of Proposition 2}

Proof. Result (i) is immediate from Corollary 1. A higher $\tau$ induces both lenders to offer lower interest rates (in the sense of first-order stochastic dominance) and also induces the weak lender to make offers more likely upon seeing a good signal. This benefits both types of borrowers. 
The result concerning the impact of $x_{s}$ in (ii) is also immediate from Corollary 1. A higher $x_{s}$ induces both lenders to charge higher interest rates and also induces the weak lender to make offers less likely upon seeing a good signal. This harms both types of borrowers.

When $x_{w}$ increases, we know from Corollary 1 that interest rates go up and the weak lender offers loans more likely upon seeing a good signal, and so the high-type must become better off. But now the weak lender receives a high signal less likely from a low-type borrower, and this negatively impacts the low-type borrowers. A straightforward calculation of the derivative of $V_{l}$ with respect to $x_{w}$ yields the cut-off result.

\section{A.6 Proof of Corollary 2}

Proof. The result concerning the impact of $\Delta$ is immediately from Proposition 2 since for a fixed $x_{w}$ increasing $\Delta$ is the same as increasing $x_{s}$.

The result concerning the impact of the base screening ability $x_{w}$ is less straightforward. For notational simplicity, in the proof let $x=x_{w}$ represent the base screening ability. Notice that

$$
V_{h}(x, \Delta, \tau)-\delta=\bar{r}\left(1-\frac{1-x}{\bar{r} \tau}\right)[1-\phi(\bar{r})]
$$

where

$$
\phi(\bar{r})=\frac{x+\Delta}{\frac{\tau}{1-x} \bar{r}-1+x+\Delta} .
$$

Its derivative with respect to $x$ equals

$$
\frac{[\bar{r} \tau-(1-x)][\Delta(1-x+\bar{r} \tau)+2 \bar{r} \tau x]}{\tau\left[\Delta(1-x)-(1-x)^{2}+\bar{r} \tau\right]^{2}}>0,
$$

where the inequality is from $0<x<1$ and Assumption 1 which implies $\bar{r} \tau-(1-x)>0$.

For the low-type borrowers,

$$
\frac{1}{\delta} V_{l}(x, \Delta, \tau)=1-(x+\Delta)[x+(1-x) \phi(\bar{r})],
$$

Its derivative with respect to $x$ equals

$$
-\frac{[\bar{r} \tau-(1-x)][\Delta(1-x+\bar{r} \tau)+2 \bar{r} \tau x]}{\left[\Delta(1-x)-(1-x)^{2}+\bar{r} \tau\right]^{2}}<0 .
$$




\section{A.7 Proof of Lemma 2}

Proof. Let us define the $\phi$ function and the lower bound of the interest rate distribution in each market segment as follows:

$$
\phi_{+}(r)=\phi\left(r ; x_{b}, x_{f}^{\prime}, \tau_{+}\right), \phi_{-}(r)=\phi\left(r ; x_{f}, x_{b}, \tau_{-}\right),
$$

and

$$
\underline{r}_{+}=\frac{1-x_{b}}{\tau_{+}}, \underline{r}_{-}=\frac{1-x_{f}}{\tau_{-}}
$$

When low-type borrowers are indifferent between signing up or not, from $V_{l}$ defined in (10) we know

$$
x_{f}^{\prime}\left[x_{b}+\left(1-x_{b}\right) \phi_{+}(\bar{r})\right]=x_{b}\left[x_{f}+\left(1-x_{f}\right) \phi_{-}(\bar{r})\right] .
$$

Given $x_{f}^{\prime}>x_{b}>x_{f}$ and $\phi_{+}(\bar{r}), \phi_{-}(\bar{r}) \leq 1$, we deduce that

$$
x_{b}+\left(1-x_{b}\right) \phi_{+}(\bar{r})<x_{f}+\left(1-x_{f}\right) \phi_{-}(\bar{r}) \leq x_{b}+\left(1-x_{b}\right) \phi_{-}(\bar{r}),
$$

and so

$$
\phi_{-}(\bar{r})>\phi_{+}(\bar{r}) .
$$

Using the expression for the $\phi$ function, we get

$$
\phi_{-}(\bar{r})=\frac{x_{b}}{\frac{\bar{r}}{\underline{r}_{-}}-\left(1-x_{b}\right)}>\phi_{+}(\bar{r})=\frac{x_{f}^{\prime}}{\frac{\bar{r}}{\underline{r}_{+}}-\left(1-x_{f}^{\prime}\right)}>\frac{x_{b}}{\frac{\bar{r}}{\underline{r}_{+}}-\left(1-x_{b}\right)},
$$

where the second inequality used $x_{f}^{\prime}>x_{b}$ and $\frac{\bar{r}}{\underline{r}_{+}}>1$. Hence,

$$
\underline{r}_{-}>\underline{r}_{+} \cdot
$$

Then from (31), (32) and $V_{h}$ defined in (9), we derive

$$
V_{h}\left(x_{b}, x_{f}^{\prime}, \tau_{+}\right)-\delta=\left(\bar{r}-\underline{r}_{+}\right)\left(1-\phi_{+}(\bar{r})\right)>V_{h}\left(x_{f}, x_{b}, \tau_{-}\right)-\delta=\left(\bar{r}-\underline{r}_{-}\right)\left(1-\phi_{-}(\bar{r})\right)
$$

i.e. high-type borrowers with a zero sign-up cost must strictly prefer to sign up.

\section{A.8 Proof of Proposition 4}

Proof. (i) Here we prove that there is a non-empty set of primitive parameters such that (14)(17) hold. (We relegate to the online appendix the detailed characterization of the range of the parameters and the condition for uniqueness.) 
First, by continuity we can focus on the edge case with $x_{b}=x_{f}$. (Our argument below continues to work when $x_{b}$ and $x_{f}$ are sufficiently close to each other.)

Second, given $V_{h}$ decreases in the strong lender's screening ability and $x_{f}^{\prime}>x_{b}$, (17) must hold if $\tau_{+}$is sufficiently close to $\tau$. This can be achieved if we let $\sigma_{l}$ be sufficiently close to 1 .

Third, we choose $\tau_{-}<\tau$ so that the equality of (16) holds. (This is feasible given (1). By continuity the argument also works for a slightly bigger $\tau_{-}$, in which case (16) holds.) The advantage of choosing $\tau_{-}$in this way is that we have $V_{h}\left(x_{f}, x_{b}, \tau_{-}\right)-\delta=0$ in the opt-out market segment so that (14) must hold. When $\sigma_{h}=1$, we have

$$
\tau_{-}=\tau \cdot \frac{\rho}{1-(1-\rho) \sigma_{l}}
$$

Then for any $\tau_{-}<\tau$ and $\sigma_{l} \in(0,1)$, we must be able to find a $\rho \in(0,1)$ which solves the above equation.

Finally, we need to ensure that (15) holds for some parameters. The remaining parameter we can choose is $x_{f}^{\prime}$. When the equality of (16) holds, one can check that $V_{l}\left(x_{f}, x_{b}, \tau_{-}\right) / \delta=1-x_{b}$. Then (15) requires

$$
x_{f}^{\prime}\left(x_{b}+\left(1-x_{b}\right) \frac{x_{f}^{\prime}}{\frac{\bar{r} \tau_{+}}{1-x_{b}}-1+x_{f}^{\prime}}\right)=x_{b} .
$$

Notice that when $\tau_{+}=\tau$, given (1), there exists $\varepsilon>0$ such that the above equation has a solution $x_{f}^{\prime} \in\left(x_{b}+\varepsilon, 1\right) .{ }^{32}$ The same argument works if $\tau_{+}$is sufficiently close to $\tau$. That is, for a $\tau_{+} \approx \tau$ (or $\sigma_{l} \approx 1$ ) chosen in the second step, the above equation has a solution $x_{f}^{\prime}$ bounded away from $x_{b}$ so that (15) holds.

(ii) Before open banking, the bank earns $\pi_{b}^{0}=\frac{\Delta}{1+\tau}$ and the fintech earns $\pi_{f}^{0}=0$. After open banking, let $n_{+}$and $n_{-}$be the measure of consumers who sign up and who do not, respectively. (They satisfy $n_{+}+n_{-}=1$.) Notice that we must have $n_{+}\left(1-\theta_{+}\right)+n_{-}\left(1-\theta_{-}\right)=1-\theta$, where $\theta_{+}$and $\theta_{-}$are respectively the fraction of high-type borrowers in each market segment. This is equivalent to

$$
\frac{n_{+}}{1+\tau_{+}}+\frac{n_{-}}{1+\tau_{-}}=\frac{1}{1+\tau} .
$$

In the sign-up market segment, the two lenders' profits are respectively

$$
\pi_{b}^{+}=0, \pi_{f}^{+}=n_{+} \frac{\Delta^{\prime}}{1+\tau_{+}}
$$

\section{2}

Proof. This is because when $x_{f}^{\prime}=1$, the left-hand side must be strictly greater than $x_{b}$; when $x_{f}^{\prime}=x_{b}+\varepsilon$, the left-hand side must be strictly less than $x_{b}+\varepsilon$ for some $\varepsilon>0$. 
In the opt-out market segment, the two lenders' profits are respectively

$$
\pi_{b}^{-}=n_{-} \frac{\Delta}{1+\tau_{-}}, \pi_{f}^{-}=0
$$

It is clear that the fintech earns a higher profit than before, while the bank's profit drops as

$$
\pi_{b}^{0}=\frac{\Delta}{1+\tau}>\pi_{b}^{+}+\pi_{b}^{-}=n_{-} \frac{\Delta}{1+\tau_{-}},
$$

where the inequality used (33).

Industry profit goes up if and only if

$$
\pi_{f}^{+}+\pi_{b}^{-}=n_{+} \frac{\Delta^{\prime}}{1+\tau_{+}}+n_{-} \frac{\Delta}{1+\tau_{-}}>\pi_{b}^{0}=\frac{\Delta}{1+\tau} .
$$

Given (33), this is the case if $\Delta^{\prime}>\Delta$, which must be true in our equilibrium where the high-type borrowers who sign up suffer from open banking. (This is because from Corollary 2, we know that $V_{h}$ increases in the base screening ability and the average credit quality but decreases in the ability gap. In the sign-up market segment, the base ability improves from $x_{f}$ to $x_{b}$ and the average credit quality improves from $\tau$ and $\tau_{+}$, and so the high-type borrowers become worse off only if $\Delta^{\prime}>\Delta$.)

The result concerning market efficiency follows from the same argument as in the case of compulsory sign-up.

\section{A.9 Proof of Proposition 5}

Before open banking, fintech cannot condition its strategy on the $\xi$-event. Similar results as Lemma 3 apply here: when making an offer, lenders randomize over common support $\left[\underline{r}^{\xi}, \bar{r}\right]$, and at most one of them can have a mass point at the top $r=\bar{r}$.

\section{The case of $\xi<\phi(\bar{r})$ :}

Proof. From the discussion of $\xi$ 's critical value (see Equation 19), if $\xi<\phi(\bar{r})$, fintech's profit in the $\xi$-event is dominated by the winner's curse in the non-- $\xi$-event when evaluated at $r=\bar{r}$. Hence, by the same argument in Proposition 1, one lender makes zero profit and randomly drops out upon seeing a good signal, and the other lender earns a positive profit, always makes an offer and has a mass point at $r=\bar{r}$, such that both lenders to be willing to offer at $r=\bar{r}$. Similar to the argument in Lemma 1, if $\pi_{f}^{\xi}>\pi_{b}^{\xi}=0$, then $(1-\xi) \pi_{f}^{\xi}>\pi_{b}^{\xi}$, which further implies $p_{L H}<p_{H L}$, contradiction. Therefore, following Proposition 1, there exists a unique mixed strategy equilibrium with fintech randomly dropping out $m_{f}^{\xi}<1$ and traditional bank's mass point $\lambda_{b}^{\xi}$ at the top.

The equilibrium characterization largely follows from the baseline model. Recall $\phi(r)=\frac{x_{b}}{\frac{\tau}{1-x_{f}} r-\left(1-x_{b}\right)}$ 
given in (6). Then (20) yields:

$$
\bar{F}_{b}^{\xi}(r)=\frac{\phi(r)-\xi}{1-\xi}=\frac{1}{1-\xi}\left(\frac{x_{b}}{\frac{\tau}{1-x_{f}} r-\left(1-x_{b}\right)}-\xi\right),
$$

which is well defined when $\xi \leq \phi(\bar{r})<1 ; F_{b}^{\xi}$ has a mass point at $r=\bar{r}$ with the size of

$$
\lambda_{b}^{\xi}=\frac{\phi(\bar{r})-\xi}{1-\xi} .
$$

The traditional bank's indifference condition (21) is the same as in the baseline, so fintech's strategy must be the same as in the baseline: upon seeing a good signal, it makes an offer with probability $m_{f}^{\xi}=1-\phi(\bar{r})$, and the offer randomizes over $\left[\underline{r}^{\xi}, \bar{r}\right]$ according to

$$
\bar{F}_{f}^{\xi}(r)=\frac{\phi(r)-\phi(\bar{r})}{1-\phi(\bar{r})}
$$

We now derive the borrower surplus. As the mixed-strategy equilibrium here only differs from the baseline case in $\bar{F}_{b}^{\xi}(r)=\frac{\phi(r)-\xi}{1-\xi}$ (and $\lambda_{b}^{\xi}=\frac{\phi(\bar{r})-\xi}{1-\xi}$ ), it is convenient to illustrate the borrower surplus as the benchmark surplus $V_{i}$ plus a wedge due to the $\xi$-event. The high-type borrowers care about the expected interest rate, so

$$
V_{h}^{\xi}(\tau)=\left(1-\xi+\xi m_{f}^{\xi}\right) \bar{r}-\underbrace{\left\{(1-\xi) \cdot\left[\left(1-m_{f}^{\xi}\right) \mathbb{E}\left[r_{b}^{\xi}\right]+m_{f}^{\xi} \mathbb{E}\left[\min \left\{r_{b}^{\xi}, r_{f}^{\xi}\right\}\right]\right]+\xi \cdot m_{f}^{\xi} \cdot \mathbb{E}\left[r_{f}^{\xi}\right]\right\}}_{\text {expected interest rate }}
$$

where the second term in the curly bracket corresponds to the $\xi$-event in which there is only one lender. Plugging in $\bar{F}_{j}^{\xi}(r)$ and $m_{f}^{\xi}$ yields $V_{h}^{\xi}(\tau)=V_{h}(\tau)$. Low-type borrowers only care about the probability of receiving a loan, so

$$
V_{l}^{\xi}(\tau)=(1-\xi) V_{l}\left(x_{f}, x_{b}, \tau\right)+\xi\left(1-x_{f}\right)(1-\phi(\bar{r})) \delta
$$

In the $1-\xi$ event, the equilibrium differs from baseline equilibrium only in $\bar{F}_{b}^{\xi}(r)$, and thus a low type who does not care about pricing has the same surplus $V_{l}\left(x_{f}, x_{b}, \tau\right)$ as in baseline; in the $\xi$ event, the fintech is the only lender, and the borrower only receives the loan when (wrongly) tested with $H$ (probability $1-x_{f}$ ) and the fintech does make the offer (probability $m_{f}^{\xi}=1-\phi(\bar{r})$ ).

\section{The case of $\xi=\phi(\bar{r})$ :}

Proof. When $\xi=\phi(\bar{r})$, from lenders' indifference conditions (20) and (21), we know lender profits $\pi_{b}^{\xi}, \pi_{f}^{\xi}$, lowest interest rate $\underline{r}^{\xi}$, and bank pricing distribution $\bar{F}_{b}^{\xi}(r)$ are the same form as when $\xi<\phi(\bar{r})$. At $r=\bar{r}$, the size of bank's mass point shrinks to $\lambda_{b}^{\xi}=0$ exactly, and it follows that the fintech may also yield borrowers to the traditional bank (to make the latter participate) by a mass point at $\bar{r}$, in addition to randomly dropping out upon $H$ as in the case of $\xi<\phi(\bar{r})$. Hence, there 
exists a continuum of equilibria indexed by $m_{f}^{\xi} \in[1-\phi(\bar{r}), 1]$ that satisfy $1-m_{f}^{\xi}+m_{f}^{\xi} \lambda_{f}^{\xi}=\phi(\bar{r})$. Accordingly $\lambda_{f}^{\xi}=1-\frac{1-\phi(\bar{r})}{m_{f}^{\xi}}$, and $\bar{F}_{f}^{\xi}(r)=1-\frac{1-\phi(r)}{m_{f}^{\xi}}$ from rescaling (still $1-m_{f}^{\xi}+m_{f}^{\xi} \bar{F}_{f}^{\xi}(r)=\phi(r)$ as in $\xi<\phi(\bar{r}))$. This completes the characterization of the mixed strategy equilibrium.

The choice of $m_{f}^{\xi}$ affects the probability of receiving the loan and hence low-type's surplus, while high type still earns $V_{h}^{\xi}(\tau)=V_{h}(\tau)$. Specifically,

$$
V_{l}^{\xi}(\tau)=\delta\left\{1-x_{b}\left[x_{f}+\left(1-x_{f}\right)\left(1-m_{f}^{\xi}\right)\right]\right\}
$$

\section{The case of $\xi>\phi(\bar{r})$ :}

Proof. Similar to Varian (1980), the unique equilibrium is a mixed-strategy one on common support $\left[\underline{r}^{\xi}, \bar{r}\right] ; \underline{r}^{\xi}$ will be shown to be different from other cases shortly. First, we argue that both lenders have positive profits and always make an offer upon seeing a good signal, so $m_{j}^{\xi}=1$ for $j \in\{b, f\}$. To see this, one feasible strategy for the fintech is to always offer $r=\bar{r}$ upon seeing a good signal, and the associated profit is no less than

$$
p_{H H} \xi\left[\mu_{H H}(\bar{r}+1)-1\right]-p_{L H}=(1-\theta) x_{b}\left(1-x_{f}\right)(\underbrace{\frac{\xi}{\phi(\bar{r})}}_{>1}-1)>0 .
$$

To make the traditional bank willing to offer at $r=\bar{r}$, fintech has a mass point $\lambda_{f}^{\xi}$ at $\bar{r}$ and the traditional bank is open at $\bar{r}$. The traditional bank must also make positive profit $\pi_{b}^{\xi}>0$ due to better screening ability. ${ }^{33}$

The fintech's indifference condition is

$$
r \in\left(\underline{r}^{\xi}, \bar{r}\right): \pi_{f}^{\xi}=p_{H H}\left[\xi+(1-\xi) \bar{F}_{b}^{\xi}(r)\right]\left[\mu_{H H}(r+1)-1\right]-p_{L H},
$$

Evaluating (34) at $r=\bar{r}$ yields the fintech's profit

$$
\pi_{f}^{\xi}=\xi \cdot \frac{\tau \bar{r}-\left(1-x_{f}\right)}{1+\tau}-(1-\xi) \cdot \frac{x_{b}\left(1-x_{f}\right)}{1+\tau},
$$

which allows us to solve for $\underline{r}^{\xi}$ (as the fintech is earning $\pi_{f}^{\xi}$ at $\underline{r}^{\xi}$ as well):

$$
\underline{r}^{\xi}=\xi \bar{r}+(1-\xi) \frac{\left(1-x_{b}\right)\left(1-x_{f}\right)}{\tau} .
$$

Note that the lower bound here is higher than that in the baseline, $\underline{r}^{\xi}>\underline{r}$, because at lower bound interest rate the fintech serves all borrowers tested with $S_{f}=H$ in both cases but here $\pi_{f}^{\xi}>0$.

\footnotetext{
${ }^{33}$ To see this, consider when a lender posts $r=\underline{r}^{\xi}$ and gets to serve all borrowers tested with $H H$. Then adjusting for market size, the traditional bank suffers from less serious winner's curse.
} 
Lastly, the fintech is indifferent across $r \in\left[\underline{r}^{\xi}, \bar{r}\right)$, implying

$$
\bar{F}_{b}^{\xi}(r)=\frac{\xi}{1-\xi} \cdot \frac{\phi(r)-\phi(\bar{r})}{\phi(\bar{r})}
$$

The bank's indifference condition is

$$
r \in\left(\underline{r}^{\xi}, \bar{r}\right): \pi_{b}^{\xi}=(1-\xi)\left\{p_{H H} \bar{F}_{f}^{\xi}(r)\left[\mu_{H H}(r+1)-1\right]-p_{H L}\right\}
$$

Using this condition at $r=\underline{r}^{\xi}$, we have bank profit

$$
r=\underline{r}^{\xi}: \pi_{b}^{\xi}=(1-\xi) p_{L H}\left(\frac{\xi}{\phi(\bar{r})}-\frac{p_{H L}}{p_{L H}}\right)
$$

The bank's indifference condition across $r \in\left[\underline{r}^{\xi}, \bar{r}\right)$ pins down the fintech's strategy

$$
\bar{F}_{f}^{\xi}(r)=\frac{\xi \phi(r)}{\phi(\bar{r})}
$$

with the mass point $\lambda_{f}=\xi$. Note that $\bar{F}_{f}^{\xi}(r)$ strictly increases in $\xi$, so with a larger $\xi$ the fintech offers loans at higher interest rates in the sense of first order stochastic dominance.

As for borrower surplus, a high-type borrower always receives a loan and cares about the expected interest rate,

$$
\begin{aligned}
V_{h}^{\xi}(\tau) & =\bar{r}-\left[(1-\xi) \mathbb{E}\left[\min \left\{r_{b}^{\xi}, r_{f}^{\xi}\right\}\right]+\xi \mathbb{E}\left[r_{f}^{\xi}\right]\right] \\
& =(1-\xi)^{2}\left[\bar{r}-\frac{\left(1-x_{b}\right)\left(1-x_{f}\right)}{\tau}\right]
\end{aligned}
$$

a low-type borrower receives a loan when in the $\xi$-event she is tested $H$ with the fintech, or when otherwise she is tested $H$ with at least one of the lenders,

$$
V_{l}^{\xi}(\tau)=\delta\left[\xi\left(1-x_{f}\right)+(1-\xi)\left(1-x_{b} x_{f}\right)\right]
$$

In addition, we show that high types are worse off due to the very likely privacy event, i.e. $V_{h}^{\xi}(\tau)<V_{h}(\tau)$ when $\xi>\phi(\bar{r})$. Recall that the expected interest rate in the baseline is 
$m_{f} \mathbb{E}\left[\min \left\{r_{b}, r_{f}\right\}\right]+\left(1-m_{f}\right) \mathbb{E}\left[r_{b}\right]=\underline{r}+\int_{\underline{r}}^{\bar{r}} \phi^{2}(r) d r$, and the expected interest rate here is

$$
\begin{aligned}
(1-\xi) \mathbb{E}\left[\min \left\{r_{b}^{\xi}, r_{f}^{\xi}\right\}\right]+\xi \mathbb{E}\left[r_{f}^{\xi}\right] & =\underline{r}^{\xi}+\frac{\xi^{2}}{\phi^{2}(\bar{r})} \int_{\underline{\underline{r}} \xi}^{\bar{r}} \phi^{2}(r) d r \\
& =\underline{r}+\underbrace{\int_{\underline{r}}^{\underline{r}^{\xi}} d r}_{\underline{r}^{\xi}>\underline{r}}+\underbrace{\frac{\xi^{2}}{\phi^{2}(\bar{r})}}_{\underline{1}} \int_{\underline{r}^{\xi}}^{\bar{r}} \phi^{2}(r) d r \\
& >\underline{r}+\int_{\underline{r}}^{\underline{r}^{\xi}} \phi^{2}(r) d r+\int_{\underline{\underline{r}} \xi}^{\bar{r}} \phi^{2}(r) d r \\
& =\underline{r}+\int_{\underline{r}}^{\bar{r}} \phi^{2}(r) d r .
\end{aligned}
$$

Note that there is a discontinuous downward jump in $V_{h}^{\xi}(\tau)$ at the threshold $\xi=\phi(\bar{r})$ : for a smaller $\xi$ the $\xi$-event does not affect borrower surplus but a larger $\xi$ makes her worse off.

\section{A.10 Proof of Proposition 6}

Proof. 1. When $\xi \leq \phi(\bar{r})$, the fintech earns a zero profit before open banking but a positive profit after, and the bank makes the same profit in either case. When $\xi>\phi(\bar{r})$, from (26) and (35) it is immediate to see that the fintech benefits from open banking; while the bank suffers as

$$
\pi_{b}^{\xi}=(1-\xi)\left\{p_{H H}\left[\mu_{H H}\left(\underline{r}^{\xi}+1\right)-1\right]-p_{H L}\right\}>\pi_{b}^{\xi, O B}=(1-\xi)\left\{p_{H H}\left[\mu_{H H}(\underline{r}+1)-1\right]-p_{H L}\right\},
$$

where $\underline{r}^{\xi}>\underline{r}$ as shown in Proposition 5 .

2. When $\xi \leq \phi(\bar{r})$, it is straightforward to check that $V_{h}^{\xi, O B}(\tau)<V_{h}^{\xi}(\tau)$ in $(22)$ and $V_{l}^{\xi, O B}(\tau)>V_{l}^{\xi}(\tau)$ from fintech's offering probability in the $\xi$-event. When $\xi>\phi(\bar{r})$, the low type suffer from open banking because by comparing (25) and (28), we have

$$
V_{l}^{\xi}=\delta(1-\xi)\left(1-x_{b} x_{f}\right)+\delta \xi\left(1-x_{f}\right)>(1-\xi) V_{l}(\tau)+\delta \xi\left(1-x_{f}\right)=V_{l}^{\xi, O B}(\tau),
$$

where the inequality holds as $\delta\left(1-x_{b} x_{f}\right)$ is greater than $V_{l}(\tau)$ in (10). (The equality will hold if $\tau \rightarrow \infty$. $)^{34}$ The high type suffer from open banking if

$$
V_{h}^{\xi}(\tau)=(1-\xi)^{2}\left[\bar{r}-\frac{\left(1-x_{b}\right)\left(1-x_{f}\right)}{\tau}\right]>(1-\xi) V_{h}(\tau)=V_{l}^{\xi, O B}(\tau)
$$

which is equivalent to

$$
(1-\xi)\left(\bar{r}-\underline{r}+x_{b} \underline{r}\right)>V_{h}(\tau)=(\bar{r}-\underline{r})(1-\phi(\bar{r})) .
$$

\footnotetext{
${ }^{34}$ In the knife edge case open banking may hurt or benefit low-type depending on the equilibrium $m_{f}^{\xi} \in[1-\phi(\bar{r}), 1]$.
} 
This holds if and only if $\xi$ is below some threshold $\hat{\xi} \in(\phi(\bar{r}), 1)$.

3. This result directly follows from result 2).

\section{A.11 Proof of Proposition 7}

For notational convenience, we denote by $\Delta V_{i}^{\xi, O B} \triangleq V_{i}^{\xi, O B}\left(\tau_{+}\right)-V_{i}^{\xi}\left(\tau_{-}\right)$the $i$-type's incentive to sign up. The sign-up equilibrium is a collection of tech-savvy borrowers' sign-up decisions $\left\{\sigma_{i}\right\}$, and beliefs about the average credit quality in each market segment $\left\{\tau_{-}, \tau_{+}\right\}$, such that a) $\left\{\tau_{-}, \tau_{+}\right\}$are determined by the Bayes' rule and characterized in (12); b) $\left\{\sigma_{i}\right\}$ satisfy borrowers' incentive compatibility conditions that are similar to (13) with surplus $V_{i}^{\xi}\left(\tau_{-}\right)$for not signing up and $V_{i}^{\xi, O B}\left(\tau_{+}\right)$for signing up, given lenders' pricing strategies $\left\{m_{j+}^{\xi, O B}, \lambda_{j+}^{\xi, O B}, F_{j+}^{\xi, O B}\right\}$ and $\left\{m_{j-}^{\xi, O B}, \lambda_{j-}^{\xi, O B}, F_{j-}^{\xi, O B}\right\}$ respectively for borrowers who opted in and who opted out.

Contrary to Subsection 4.3.1, now the threshold of $\xi$ which decides the lender strategy in the optout segment is endogenous and depends on $\tau_{-}$(for borrowers who signed up, $\xi$ does not affect the structure of lender competition). We first characterize the case with $\xi<\phi(\bar{r} ; \tau)$ and the case with $\xi>\phi(\bar{r} ; \rho \tau)$, where lender strategies in the opt-out segment respectively follow Case 1 and Case 3 in Proposition 5; then we characterize the equilibrium in the case with $\phi(\bar{r} ; \tau) \leq \xi \leq \phi(\bar{r} ; \rho \tau)$.

Small $\xi$ Case: $\xi<\phi(\bar{r} ; \tau)$

Proof. First we show that when $\tau_{-} \leq \tau$, low-type has a higher willingness to sign up. The $\xi$ threshold of lender strategy in the opt-out pool is $\phi\left(\bar{r} ; \tau_{-}\right)$. Note that Condition 29 ensures $\bar{r} \tau_{-} \geq$ $1-x_{f}$. When $\tau_{-} \leq \tau$, we have $\phi\left(\bar{r} ; \tau_{-}\right) \geq \phi(\bar{r} ; \tau)>\xi$, so for the opting out borrowers, lender strategy and borrower surplus follow Case 1 in Proposition 5. Then for high-type to be willing to sign up,

$$
V_{h}^{\xi}\left(\tau_{-}\right)=V_{h}\left(\tau_{-}\right) \stackrel{\text { willing to sign up }}{\leq}(1-\xi) V_{h}\left(\tau_{+}\right)=V_{h}^{\xi, O B}\left(\tau_{+}\right) .
$$

Hence $V_{h}\left(\tau_{-}\right)<V_{h}\left(\tau_{+}\right)$and $\tau_{-}<\tau_{+}$. With the better inference and the effects of $\xi$-event on low type shown in (23) and (28), low-type must strictly prefer to sign up:

$$
V_{l}^{\xi}\left(\tau_{-}\right)<V_{l}\left(\tau_{-}\right)<V_{l}\left(\tau_{+}\right)<V_{l}^{\xi, O B}\left(\tau_{+}\right)
$$

This result rules out equilibrium where a higher proportion of high-type borrowers sign up, $\sigma_{h} \geq$ $\sigma_{l}>0$, under which $\tau_{-} \leq \tau$ follows and low-type has higher willingness to sign up. If $1>\sigma_{h}>0$, then low-type must strictly prefer signing up and $\sigma_{l}=1>\sigma_{h}$. If $\sigma_{h}=1$, then $\sigma_{l}=1$, but $\tau_{-}=\tau_{+}=\tau$ contradicts with high type's sign up incentive.

We now rule out that a larger proportion of low-type signing up in equilibrium, i.e., $\sigma_{l}>\sigma_{h}>0$ and hence $\tau_{-}>\tau>\tau_{+}$. In this case, the endogenous $\xi$ threshold $\phi\left(\bar{r} ; \tau_{-}\right)<\phi(\bar{r} ; \tau)$ and lender competition in the opt-out pool may not always follow one case in Proposition 5. If $\xi<\phi\left(\bar{r} ; \tau_{-}\right)$, the competition follows Case 1 in Proposition 5, but $\tau_{-}>\tau>\tau_{+}$violates high-type's sign up incentive. If $\xi=\phi\left(\bar{r} ; \tau_{-}\right)$we show later that it must be $\sigma_{l}<\sigma_{h}$; and if $\phi\left(\bar{r} ; \tau_{-}\right)<\xi<\phi(\bar{r} ; \tau)$, we 
show later that $\sigma_{h}=1, \sigma_{l}=0$. The last two cases have $\sigma_{l}<\sigma_{h}$ hence contradict with the premise that "larger proportion of low-type signing up in equilibrium."

Hence the only possible equilibria is $\sigma_{h}=\sigma_{l}=0$ and $\tau_{-}=\tau_{+}=\tau$, under which lender strategy is Case 1 in Proposition 5. Introduce $\hat{\tau}$ as the threshold $\tau_{+}$for high-type to be indifferent to sign up, so

$$
V_{h}(\tau)=(1-\xi) V_{h}(\hat{\tau})
$$

If the off-equilibrium belief for anyone who signs up satisfy $\tau_{+}<\hat{\tau}$, high-type borrower does not sign up, and low-type also does not want to sign up to be revealed.

Therefore, in the unique equilibrium nobody signs up and the off-equilibrium belief satisfies $\tau_{+}<\hat{\tau}$.

Large $\xi$ Case: $\xi>\phi(\bar{r} ; \rho \tau)$

Proof. Note that $\tau_{-}=\rho \tau$ is the lower bound of $\tau_{-}$, and is reached when all tech savvy high-type sign up, $\sigma_{h}=1$, but none of the low-type signs up, $\sigma_{l}=0$. Hence, for any possible equilibrium belief $\tau_{-}$, we have $\xi>\phi(\bar{r} ; \rho \tau) \geq \phi\left(\bar{r} ; \tau_{-}\right)$: lender competition for borrowers who did not sign up always follows Case 3 in Proposition 5.

Eq. (38) says it is a dominant strategy for the $l$-type borrower not to sign up, $\sigma_{l}=0$. Then if anyone were to sign up, it must be a high-type borrower and $\tau_{+}=\infty$. As a result, in the non$\xi$-event, lenders compete for the opt-in segment a la Bertrand: lenders always charge $r=\underline{r}^{\xi}, O B=$ $\frac{1-x_{f}}{\tau_{+}}=0$. Then the expected interest rate after open banking is $\xi \bar{r}$, and is smaller than that before open banking, $(1-\xi) \mathbb{E}\left[\min \left\{r_{b}^{\xi}, r_{f}^{\xi}\right\}\right]+\xi \mathbb{E}\left[r_{f}^{\xi}\right]$ :

$$
\begin{aligned}
\xi \bar{r}-\left[(1-\xi) \mathbb{E}\left[\min \left\{r_{b}^{\xi}, r_{f}^{\xi}\right\}\right]+\xi \mathbb{E}\left[r_{f}^{\xi}\right]\right] & =\xi \bar{r}-\left[(2-\xi) \xi \bar{r}+(1-\xi)^{2} \frac{\left(1-x_{b}\right)\left(1-x_{f}\right)}{\tau_{-}}\right] \\
& =-\xi(1-\xi) \bar{r}-(1-\xi)^{2} \frac{\left(1-x_{b}\right)\left(1-x_{f}\right)}{\tau_{-}}<0 .
\end{aligned}
$$

Therefore in the unique sign-up equilibrium, $\sigma_{h}=1$ and $\sigma_{l}=0$.

Intermediate $\xi$ Case: $\phi(\bar{r} ; \tau)<\xi<\phi(\bar{r} ; \rho \tau)$

Proof. Step 1. We argue that in equilibrium $\xi=\phi\left(\bar{r} ; \tau_{-}\right)$always holds so that the lender competition in the opt-out segment switches structures. Otherwise, if in equilibrium $\xi<\phi\left(\bar{r} ; \tau_{-}\right)$, nobody signs up and $\tau_{-}=\tau$, which contradicts with $\phi(\bar{r} ; \tau) \leq \xi$; if $\xi>\phi\left(\bar{r} ; \tau_{-}\right)$, only tech-savvy high-type borrowers opt in and $\tau_{-}=\rho \tau$ which contradicts with $\xi \leq \phi_{-}\left(\bar{r} ; \tau_{-}=\rho \tau\right)$. Hence, when $\phi(\bar{r} ; \tau) \leq \xi \leq \phi(\bar{r} ; \rho \tau)$, in equilibrium $\xi$ is on the cutoff $\xi=\phi\left(\bar{r} ; \tau_{-}\right)$.

Step 2. We argue that in equilibrium it must be that $\sigma_{l} \in(0,1)$ and $\sigma_{h}>0$. Suppose not; we prove by contradiction.

1. Say $\sigma_{l}=0$. If $\sigma_{h}=0$, then $\tau_{-}=\tau_{+}=\tau$ and $\xi>\phi\left(\bar{r} ; \tau_{-}\right)$, lenders compete for the opt-out segment following Case 3 in Proposition 5, which leads to $\sigma_{h}=1, \sigma_{l}=0$, contradiction. If 
$\sigma_{h}>0$, then $\tau_{+}=+\infty$ and for a borrower who signs up lenders always make an offer upon $H$; it follows that low-type borrowers must be at least indifferent to sign up, contradiction.

2. Hence, $\sigma_{l}>0$ in equilibrium, which implies that some high-type borrowers must sign up (i.e., $\left.\sigma_{h}>0\right)$; otherwise the low-type fully reveal themselves in the opt-in segment and lenders do not participate.

3. We now rule out the case of $\sigma_{l}=1$, under which $\tau_{-} \geq \tau$ and $\xi>\phi(\bar{r} ; \tau) \geq \phi\left(\bar{r} ; \tau_{-}\right)$. Lender competition in the opt-out segment leads to sign-up strategies $\sigma_{h}=1, \sigma_{l}=0$, contradiction.

Step 3. Now we derive the equilibrium sign-up behaviors. From $\phi\left(\bar{r} ; \tau_{-}\right)=\xi$, we have

$$
\tau_{-}=\frac{1-x_{f}}{\bar{r}}\left(\frac{x_{b}}{\xi}+1-x_{b}\right)
$$

The fintech's offering probability $m_{f-}^{\xi, O B}$ in the opt-out segment and beliefs $\tau_{+}, \tau_{-}$make low-type borrowers indifferent (i.e., $1>\sigma_{l}>0$ ) and high-types either indifferent or strictly prefer to sign up (i.e., $\sigma_{h}>0$ ). Specifically, borrower surplus for not signing up are

$$
\begin{aligned}
& V_{h,-}^{\xi, O B}\left(\tau_{-}\right)=V_{h}\left(\tau_{-}\right) \\
& V_{l,-}^{\xi, O B}\left(\tau_{-}\right)=(1-\xi) \underbrace{\left[1-x_{b}\left(x_{f}+\left(1-x_{f}\right)\left(1-m_{f-}^{\xi, O B}\right)\right)\right]}_{\text {prob at least one loan }}+\xi \underbrace{\left(1-x_{f}\right) m_{f-}^{\xi, O B}}_{\text {prob fintech loan }},
\end{aligned}
$$

where $m_{f-}^{\xi, O B}$ versus mass point at $r=\bar{r}$ only influences the probability of receiving a loan but does not affect the expected interest rate. For borrowers who signed up, surplus $V_{i,+}^{\xi, O B}\left(\tau_{+}\right)$are the same as (27) and (28) except for adjusted belief $\tau_{+}$.

For the high-type, there are two subcases to consider.

1. Suppose that the high-type are indifferent to sign up; then $\tau_{+}$and $m_{f-}^{\xi, O B} \geq 1-\phi\left(\bar{r} ; \tau_{-}\right)$make both type of borrowers indifferent: ${ }^{35} V_{i,-}^{\xi, O B}\left(\tau_{-}\right)=V_{i,+}^{\xi, O B}\left(\tau_{+}\right), i=h, l$. Hence, we have ${ }^{36}$

$$
\phi_{+}(\bar{r})=\frac{2 x_{b}+(1+\xi)\left(1-x_{b}\right)-\sqrt{\left[2 x_{b}+(1+\xi)\left(1-x_{b}\right)\right]^{2}-4 \xi\left(x_{b}+\left(1-x_{b}\right) \xi\right)}}{2\left(x_{b}+\left(1-x_{b}\right) \xi\right)},
$$

\footnotetext{
${ }^{35}$ Equilibrium $m_{f-}^{\xi, O B}$ is well defined and unique. The low-type's indifference condition is equivalent to

$$
\Delta V_{l}^{\xi, O B}=\left(1-x_{f}\right)\left[\left(1-m_{f-}^{\xi, O B}\right)\left(\xi+(1-\xi) x_{b}\right)-(1-\xi) x_{b} \phi_{+}(\bar{r})\right],
$$

where $\phi_{+}(\bar{r}) \equiv \phi\left(\bar{r} ; \tau_{+}\right) \cdot m_{f-}^{\xi, O B} \geq 1-\phi\left(\bar{r} ; \tau_{-}\right)$is satisfied because when $m_{f-}^{\xi, O B}=1-\phi\left(\bar{r} ; \tau_{-}\right)$low type strictly prefers to sign up as $\phi_{-}(\bar{r})\left(\xi+(1-\xi) x_{b}\right)>(1-\xi) x_{b} \underbrace{\phi_{+}(\bar{r})}_{<\phi_{-}=\xi}$, and when $m_{f-}^{\xi, O B}=1$, low type strictly prefers to opt out. Note that $\Delta V_{l}^{\xi, O B}$ is monotone in $m_{f-}^{\xi, O B}$, so $m_{f-}^{\xi, O B}$ is unique.

${ }^{36}$ It follows that $\phi_{+}(\bar{r})$ satisfies the following quadratic equation,

$$
\left(x_{b}+\left(1-x_{b}\right) \xi\right) \phi_{+}^{2}-\left[2 x_{b}+(1+\xi)\left(1-x_{b}\right)\right] \phi_{+}+\xi=0 .
$$

It has two positive roots, and only the smaller root is smaller than 1 . Later we study $\tau_{+}$; since $\tau_{+}$and $\phi_{+}$are negatively related, $\tau_{+}$takes the larger root.
} 
and

$$
m_{f-}^{\xi, O B}=1-\frac{(1-\xi) x_{b} \phi_{+}(\bar{r})}{\xi+(1-\xi) x_{b}}
$$

From belief updating rules $\tau_{+}=\tau \frac{\sigma_{h}}{\sigma_{l}}$ and $\tau_{-}=\tau \frac{\rho+(1-\rho)\left(1-\sigma_{h}\right)}{\rho+(1-\rho)\left(1-\sigma_{l}\right)}$,we solve for

$$
\sigma_{h}=\frac{\frac{\tau_{+}}{\tau_{-}}-\frac{\tau_{+}}{\tau}}{(1-\rho)\left(\frac{\tau_{+}}{\tau_{-}}-1\right)} \text { and } \sigma_{l}=\frac{\frac{\tau}{\tau_{-}}-1}{(1-\rho)\left(\frac{\tau_{+}}{\tau_{-}}-1\right)}
$$

where $\tau_{-}$is determined in (39) and $\tau_{+}$is determined by (41) and (6). Note that $\frac{\partial}{\partial \tau_{-}} \phi\left(\bar{r} ; \tau_{-}\right)<$ 0 implies that $\tau_{-}<\tau<\tau_{+}$for $\xi>\phi(\bar{r} ; \tau)$ and $\phi\left(\bar{r} ; \tau_{-}\right)=\xi$. As a result, $\sigma_{h}>\sigma_{l}$ from belief updating rule $\tau_{+}=\tau \frac{\sigma_{h}}{\sigma_{l}}$. This observation completes the earlier proof of a unique sign-up equilibrium under "Small $\xi$ Case" (i.e., $\xi<\phi(\bar{r} ; \tau)$ ) where we rule out $\tau_{+}>\tau>\tau_{-}$with $\sigma_{l}>\sigma_{h}$.

2. Now suppose that $\sigma_{h}=1$. From belief updating we have

$$
\sigma_{l}=\frac{1-\frac{\tau}{\tau_{-}} \rho}{1-\rho}, \text { and } \tau_{+}=\frac{\tau(1-\rho)}{1-\frac{\tau}{\tau_{-}} \rho},
$$

and $m_{f-}^{\xi, O B}$ is determined in (42). Note that this corner equilibrium must arise when $\xi \rightarrow$ $\phi(\bar{r} ; \rho \tau)$; in this situation, we have $\tau_{-} \rightarrow \rho \tau$ and $\tau_{+} \rightarrow+\infty$, under which

$$
V_{h,+}^{\xi, O B}\left(\tau_{+}\right) \rightarrow(1-\xi) \bar{r}>V_{h,-}^{\xi, O B}\left(\tau_{-}\right)=\underbrace{\left(1-\phi\left(\bar{r} ; \tau_{-}\right)\right)}_{=1-\xi}\left(\bar{r}-\underline{r}_{-}\right),
$$

and the high-type borrowers strictly prefer to sign up. At the same time, $\sigma_{l} \rightarrow 0$ while low-type borrowers stay indifferent whether or not to sign up.

\section{A.12 Proof of Proposition 8}

Proof. First we argue that there exists a $\tilde{\xi} \in(\phi(\bar{r} ; \tau), \phi(\bar{r} ; \rho \tau))$ such that $0 \leq \sigma_{h}<1$ when $\phi(\bar{r} ; \tau) \leq \xi<\tilde{\xi}$ and $\sigma_{h}=1$ when $\tilde{\xi} \leq \xi \leq \phi(\bar{r} ; \rho \tau)$. To see this, we already argued in Appendix A.11 that $\sigma_{h}=1,0<\sigma_{l}<1$ must arise when $\xi$ is sufficiently close to $\phi(\bar{r} ; \rho \tau)$. When $\xi=\phi(\bar{r} ; \tau)$, we have $\tau_{-}=\tau$ and $\sigma_{h}=\sigma_{l}=0$. Hence by continuity of $\sigma_{h}, \sigma_{l}$ in $\xi$, there exists such a $\tilde{\xi}$ below which high-type is indifferent to sign up and above which high-type strictly prefers to sign up.

Recall that $\theta_{+}, \theta_{-}$are respectively the average quality of opt-in and opt-out borrowers. Naturally $p(\xi) \theta_{+}+(1-p(\xi)) \theta_{-}=\theta$, and thus

$$
p(\xi)=\frac{\theta-\theta_{-}}{\theta_{+}-\theta_{-}}
$$


decreases in both $\theta_{+}$and $\theta_{-}$. When $\phi(\bar{r} ; \tau) \leq \xi<\tilde{\xi}$, high-type is indifferent to sign up, so $\tau_{+}$ must decrease with $\xi$ to balance the deterioration of $\tau_{-}$. Hence, $p(\xi)$ increases in $\xi$ in this case. On the other hand, when $\xi \geq \tilde{\xi}$, we have $\sigma_{h}=1$ and $\sigma_{l}=\frac{1-\frac{\tau}{\tau_{-}} \rho}{1-\rho}$, so $p(\xi) \equiv(1-\rho)\left[\theta+(1-\theta) \sigma_{l}\right]$ decreases in $\xi$.

Then we discuss the welfare implications for $\xi \in[\phi(\bar{r} ; \tau), \tilde{\xi}]$. First, since tech savvy borrowers of both credit type are indifferent to sign up and have the same surplus as non--tech-savvy borrowers. Hence, it suffices to discuss how open banking affects the non--tech-savvy borrowers. We argue that high-type loses,

$$
\Delta V_{h}^{\xi, O B}=\underbrace{V_{h}(\tau-)}_{V_{h, \rho}^{\xi, O B}}-\underbrace{(1-\xi)^{2}\left[\bar{r}-\frac{\left(1-x_{b}\right)\left(1-x_{f}\right)}{\tau}\right]}_{V_{h, \rho}^{\xi}(\cdot)}=\frac{(1-\xi)^{2}}{\tau} \frac{\left(1-x_{b}\right)\left(1-x_{f}\right) x_{b}}{x_{b}+\xi\left(1-x_{b}\right)}\left[1-\frac{\xi}{\phi(\bar{r} ; \tau)}\right]<0 .
$$

Note that before open banking lenders always make loans upon $H$ signal when $\xi \geq \phi(\bar{r} ; \tau)$, so low-type borrowers are hurt by open banking: $\Delta V_{l}^{\xi, O B}<0$. Therefore, all borrowers are hurt by open banking when $\xi \in[\phi(\bar{r} ; \tau), \tilde{\xi}]$ even if they voluntarily choose whether or not to sign up.

Now we study firm profits. In the region of $\phi(\bar{r} ; \tau) \leq \xi \leq \phi(\bar{r} ; \rho \tau)$, we show that the open banking hurts the bank while benefits the fintech. To see this, the profits of two lenders after open banking,

$$
\begin{aligned}
& \pi_{b}^{\xi, O B}=\pi_{b+}^{\xi, O B}+\pi_{b-}^{\xi, O B}=\underbrace{n_{+}(1-\xi) \frac{x_{b}-x_{f}}{1+\tau_{+}}}_{=\pi_{b+}^{\xi, O B}}+\underbrace{n_{-}(1-\xi) \frac{x_{b}-x_{f}}{1+\tau_{-}}}_{=\pi_{f-}^{\xi, O B}}=(1-\xi) \frac{x_{b}-x_{f}}{1+\tau}, \\
& \pi_{f}^{\xi, O B}=\pi_{f+}^{\xi, O B}+\underbrace{\pi_{f-}^{\xi, O B}}_{=0}=\xi\left[\theta(1-\rho) \sigma_{h} \bar{r}-(1-\theta)(1-\rho) \sigma_{l}\left(1-x_{f}\right)\right] ;
\end{aligned}
$$

while their profits before open banking are

$$
\begin{aligned}
\pi_{b}^{\xi} & =(1-\xi)\left[\xi \frac{\bar{r} \tau}{1+\tau}-\xi \frac{1-x_{b}}{1+\tau}-(1-\xi) \frac{\left(1-x_{b}\right) x_{f}}{1+\tau}\right], \\
\pi_{f}^{\xi} & =\xi \theta \bar{r}-\xi(1-\theta)\left(1-x_{f}\right)-(1-\xi)(1-\theta) x_{b}\left(1-x_{f}\right) .
\end{aligned}
$$

We hence have that

$$
\begin{aligned}
& \Delta \pi_{b}^{\xi, O B} \equiv \pi_{b}^{\xi, O B}-\pi_{b}^{\xi}=\frac{(1-\xi)\left(1-x_{f}\right) x_{b}}{1+\tau}\left(1-\frac{\xi}{\phi(\bar{r} ; \tau)}\right)<0 \\
& \Delta \pi_{f}^{\xi, O B}=\pi_{f}^{\xi, O B}-\pi_{f}^{\xi}=\frac{\xi\left(1-x_{f}\right)}{1+\tau}(1-\rho) \sigma_{l}\left(\frac{\bar{r} \tau_{-}}{1-x_{f}}-1\right)>0 .
\end{aligned}
$$

Finally we study the total profits for the financial sector $\Delta \pi_{b}^{\xi, O B}+\Delta \pi_{f}^{\xi, O B}$, and give sufficient conditions for it to rise after open banking. Note that $\phi\left(\bar{r} ; \tau_{-}\right)=\xi$ implies that $\frac{\bar{r} \tau_{-}}{1-x_{f}}-1=\frac{\xi x_{b}}{1-\xi}$, 
we have

$$
\Delta \pi_{b}^{\xi, O B}+\Delta \pi_{f}^{\xi, O B}=\frac{(1-\xi)\left(1-x_{f}\right) x_{b}}{1+\tau}\left[1-\frac{\phi\left(\bar{r} ; \tau_{-}\right)}{\phi(\bar{r} ; \tau)}+(1-\rho) \sigma_{l}\right]
$$

From (43), we have $(1-\rho) \sigma_{l}=\frac{\tau-\tau_{-}}{\tau_{+}-\tau_{-}}$, and hence the

$$
1-\frac{\phi\left(\bar{r} ; \tau_{-}\right)}{\phi(\bar{r} ; \tau)}+(1-\rho) \sigma_{l}=\underbrace{\frac{\left(\tau-\tau_{-}\right)}{\left(\tau_{+}-\tau_{-}\right)\left(\bar{r} \tau_{-}-\left(1-x_{b}\right)\left(1-x_{f}\right)\right)}}_{\text {positive }}\left(2 \bar{r} \tau_{-}-\bar{r} \tau_{+}-\left(1-x_{b}\right)\left(1-x_{f}\right)\right)
$$

Hence it boils down to the sign of the last bracket in Eq. (44). Notice that while $\tau_{-}=\tau$ is continuous at $\xi=\phi(\bar{r} ; \tau), \tau_{+}=\tau \frac{\sigma_{h}}{\sigma_{l}}$ typically jumps upward at $\xi=\phi(\bar{r} ; \tau)$ from left. So it is non-trivial to show that the total financial sector gains even when in the neighborhood of $\xi=\phi(\bar{r} ; \tau)$.

We use the high-type's indifference curve, which says

$$
\begin{aligned}
& 1-\frac{1-x_{f}}{\bar{r} \tau_{-}}=\left(1-\frac{1-x_{f}}{\bar{r} \tau_{+}}\right)\left(\frac{\bar{r} \tau_{+}-\left(1-x_{f}\right)}{\bar{r} \tau_{+}-\left(1-x_{f}\right)\left(1-x_{b}\right)}\right) \\
& \Leftrightarrow Q\left(\tau_{+}\right) \equiv\left(\bar{r} \tau_{+}\right)^{2}-\left[\left(1+x_{b}\right) \bar{r} \tau_{-}+\left(1-x_{b}\right)\left(1-x_{f}\right)\right] \bar{r} \tau_{+}+\left(1-x_{f}\right) \bar{r} \tau_{-}=0 .
\end{aligned}
$$

We then try to ensure that $\tau_{+}<2 \tau_{-}-\frac{\left(1-x_{b}\right)\left(1-x_{f}\right)}{\bar{r}}$ (so that the last bracket in Eq. (44) is positive), by checking the sign of $Q\left(\tau_{+}=2 \tau_{-}-\frac{\left(1-x_{b}\right)\left(1-x_{f}\right)}{\bar{r}}\right)$, which equals

$$
\begin{aligned}
& \left(2 \bar{r} \tau_{-}-\left(1-x_{b}\right)\left(1-x_{f}\right)\right)^{2}-\left[\left(1+x_{b}\right) \bar{r} \tau_{-}+\left(1-x_{b}\right)\left(1-x_{f}\right)\right]\left(2 r \tau_{-}-\left(1-x_{b}\right)\left(1-x_{f}\right)\right)+\left(1-x_{f}\right) \bar{r} \tau_{-} \\
= & \bar{r} \tau_{-}[\underbrace{2\left(1-x_{b}\right) \bar{r} \tau_{-}-\left(5-x_{b}\right)\left(1-x_{b}\right)\left(1-x_{f}\right)+\left(1-x_{f}\right)}_{M(\xi)}]+\underbrace{2\left(1-x_{b}\right)^{2}\left(1-x_{f}\right)^{2}}_{>0} .
\end{aligned}
$$

Because $Q(\cdot)$ is quadratic and open-upward, and we take the larger solution (see footnote 36), to ensure $Q\left(\tau_{+}=2 \tau_{-}-\frac{\left(1-x_{b}\right)\left(1-x_{f}\right)}{\bar{r}}\right)>0$ we need

$$
M(\xi) \equiv 2\left(1-x_{b}\right) \bar{r} \tau_{-}(\xi)-\left(5-x_{b}\right)\left(1-x_{b}\right)\left(1-x_{f}\right)+\left(1-x_{f}\right)>0
$$

for $\tau_{-}(\xi)$ when $\xi \in[\phi(\bar{r} ; \tau), \tilde{\xi}]$. (Note, $\left(1-x_{b}\right)^{2}\left(1-x_{f}\right)^{2}$ will be at higher order when $x_{j}$ 's are close to 1 , hence can be ignored). Because $\tau_{-}$is decreasing in $\xi$, it is equivalent to ensure that $M(\cdot)>0$ at both ends.

1. When $\xi=\phi(\bar{r} ; \tau), \tau_{-}(\xi)=\tau$, so we require that (recall $\rho \bar{r} \tau \geq 1-x_{f}$ in (29))

$$
\frac{2}{\rho}\left(1-x_{b}\right)-\left(5-x_{b}\right)\left(1-x_{b}\right)+1>0 .
$$


2. When $\xi=\tilde{\xi}$, we have $\sigma_{h}=1$ which implies that

$$
\tau_{-}(\tilde{\xi})=\frac{\tau_{+}(\tilde{\xi})}{\tau_{+}(\tilde{\xi})-(1-\rho) \tau} \rho \bar{r} \tau \geq \frac{\tau_{+}(\tilde{\xi})}{\tau_{+}(\tilde{\xi})-(1-\rho) \tau}\left(1-x_{f}\right) .
$$

So $M(\tilde{\xi})>0$ requires that

$$
2\left(1-x_{b}\right) \frac{\tau_{+}(\tilde{\xi})}{\tau_{+}(\tilde{\xi})-(1-\rho) \tau}-\left(5-x_{b}\right)\left(1-x_{b}\right)+1>0
$$

which is easy to verify ex post once we solved for $\tau_{+}(\tilde{\xi})$.

In sum, the simple conditions (45) and (46) guarantee that the financial sector gains after open banking when $\xi \in[\phi(\bar{r} ; \tau), \tilde{\xi}]$ (note, these conditions are also necessary if $\rho \bar{r} \tau=1-x_{f}$ and for sufficiently large $x_{j}$ 's). 


\section{B Online Appendix}

\section{B.1 Properties of Mixed-Strategy Equilibria}

Here we show that in our baseline model any mixed-strategy equilibrium is well behaved.

Lemma 3. In any mixed-strategy equilibrium, the two lenders' interest rate distributions have the following properties:

1. they share the same lower bound $\underline{r}>0$ and the same upper bound $\bar{r}$ in their supports;

2. they have no gaps in their supports;

3. they have no mass points except that one of them can have one at $\bar{r}$.

Proof. Here we show the properties of a mixed-strategy equilibrium. (i) For the lower bound result, suppose in contrast that, say, $\underline{r}_{w}<\underline{r}_{s}$, i.e. $F_{w}$ has a smaller lower bound than $F_{s}$. Then for the weak lender, offering $r \in\left(\underline{r}_{w}, \underline{r}_{s}\right)$ is always more profitable than offering $\underline{r}_{w}$ since both lead to the same demand. This contradicts $\underline{r}_{w}$ being in the support. For the upper bound result, suppose first $\max \left\{\bar{r}_{w}, \bar{r}_{s}\right\}<\bar{r}$. If $\bar{r}_{w} \neq \bar{r}_{s}$, then for the lender with the higher upper bound, offering an interest rate slightly above its upper bound will be a profitable deviation. If $\bar{r}_{w}=\bar{r}_{s}$, since it is impossible that both distributions have a mass point at this upper bound, at least one lender will have an incentive to slightly raise its interest rate without losing any demand. Now suppose, say, $\bar{r}_{w}<\bar{r}$ and $\bar{r}_{s}=\bar{r}$. Then the support of $F_{s}$ should have a gap in $\left(\bar{r}_{w}, \bar{r}\right)$ since any interest rate in this interval is dominated by $\bar{r}$. But this is impossible in equilibrium since for at least one lender offering an interest rate slightly above $\bar{r}_{w}$ would be a profitable deviation. This proves $\bar{r}_{w}=\bar{r}_{s}=\bar{r}$.

(ii) Suppose that, say, the support of $F_{s}$ has a gap $\left(r_{1}, r_{2}\right) \subset[\underline{r}, \bar{r}]$. Then $F_{w}$ should have no weight in this interval either as any $r \in\left(r_{1}, r_{2}\right)$ will lead to the same demand for the weak lender and so a higher $r$ will be more profitable. If neither distribution has a mass point at $r_{1}$, unilaterally offering $r \in\left(r_{1}, r_{2}\right)$ will be a profitable deviation for either lender. If one distribution, say, $F_{s}$ has a mass point at $r_{1}$, unilaterally offering $r \in\left(r_{1}, r_{2}\right)$ will be a profitable deviation for the strong lender. It is impossible that both distributions have a mass point at $r_{1}$.

(iii) Suppose first that one distribution, say, $F_{s}$ has a mass point at $r=\underline{r}$. Then it will be a profitable deviation for the weak lender to offer an interest rate slightly below $\underline{r}$. Suppose then that $F_{s}$ has a mass point at $\tilde{r} \in(\underline{r}, \bar{r})$. Then for the weak lender an interest rate just slightly below $\tilde{r}$ should be more profitable than any interest rate in $[\tilde{r}, \tilde{r}+\varepsilon]$ for some $0<\varepsilon<\bar{r}-\tilde{r}$. In other words, the support of $F_{w}$ must have a gap in this interval. This, however, is impossible as we have shown in (ii). Finally it is impossible that both distributions have a mass point at $\bar{r}$. 


\section{B.2 Proof of Proposition 4}

As this part of proof is relatively independent, for notational convenience we use $\alpha \equiv x_{b}$ to denote the traditional bank's screening ability, and $\beta \equiv x_{f}, \gamma \equiv x_{f}^{\prime}$ respectively for the fintech's screening abilities before and after open banking.

There are three sets primitive parameters that are relatively independent in the conditions that we need. The first set is

$$
\Gamma \equiv(\alpha, \beta, \gamma, \theta)
$$

the second is $\bar{r}$, which mainly affects lender profits; and the last is the proportion of privacy concerned borrowers $\rho$, which affects the posterior credit quality $\tau_{-}, \tau_{+}$for given borrower decisions $\sigma_{h}, \sigma_{l}$.

We focus on equilibrium where for borrowers without privacy concern, $h$ type always sign up for open banking and $l$ type is indifferent whether or not to sign up. For illustration purpose, we rewrite borrower surplus function as (note $\sigma_{l}$ will be endogenously determined in equilibrium)

$$
\tilde{V}_{i}\left(\Gamma, \bar{r}, \rho ; \sigma_{l}\right) \equiv V_{i}
$$

where $i=h$ or $l$. Specifically, before open banking,

$$
\tilde{V}_{i}(\Gamma, \bar{r}) \equiv V_{i}(\alpha, \beta, \theta)
$$

after open banking, for the group of borrowers who signed up, we denote

$$
\tilde{V}_{i}^{+}\left(\Gamma, \bar{r} ; \sigma_{l}\right) \equiv V_{i}\left(\alpha, \gamma, \tau_{+}=\frac{\tau}{\sigma_{l}}\right)
$$

for the borrowers who did not sign up, we denote

$$
\tilde{V}_{i}^{-}\left(\Gamma, \bar{r}, \rho ; \sigma_{l}\right) \equiv V_{i}\left(\alpha, \beta, \tau_{-}=\frac{\rho \tau}{1-\sigma_{l}+\rho \sigma_{l}}\right) .
$$

Note that the private benefit of receiving the loan does not affect borrowers' sign up decisions. For notational convenience, we assume $v_{h}=0$ and $v_{l}=1$ when discussing borrowers' sign up.

\section{B.2.1 Proof of Proposition 4 Part 1 (Existence)}

\section{Step 1.}

We find the parameter conditions under which there exists an equilibrium with $\hat{\sigma}_{l} \in(0,1)$ where 1 ) for borrowers without privacy concerns, $l$-type is indifferent whether or not to sign up, $h$-type strictly prefers signing up, and 2) lenders are willing to participate. We show that 1) implies an one-to mapping between $\hat{\sigma}_{l}$ and $\rho$, while 2) implies that $\hat{\sigma}_{l}$ and $\rho$ have to satisfy another condition.

Because of the l's indifference 1$)$, in later proofs we can treat $\hat{\sigma}_{l} \in(0,1)$ as exogenous, derive 
its range that satisfies the desired property, and later transform this range to that for the primitive parameter $\rho$.

\section{Step 1.1}

Define

$$
\Delta_{V_{l}}\left(\sigma_{l}, \rho\right) \equiv \tilde{V}_{l}^{+}\left(\Gamma, \bar{r} ; \sigma_{l}\right)-\tilde{V}_{l}^{-}\left(\Gamma, \bar{r}, \rho ; \sigma_{l}\right)
$$

which satisfies

$$
\begin{aligned}
\frac{\partial \Delta_{V_{l}}\left(\sigma_{l}, \rho\right)}{\partial \sigma_{l}} & =\underbrace{\frac{\partial V_{l}\left(\alpha, \gamma, \tau_{+}\left(\sigma_{l}\right)\right)}{\partial \tau_{+}}}_{+} \underbrace{\frac{\partial \tau_{+}}{\partial \sigma_{l}}}_{-}-\underbrace{\frac{\partial V_{l}\left(\alpha, \gamma, \tau_{-}\left(\sigma_{l} ; \rho\right)\right)}{\partial \tau_{-}}}_{+} \underbrace{\frac{\partial \tau_{-}}{\partial \sigma_{l}}}_{+}<0, \\
\frac{\partial \Delta_{V_{l}}\left(\sigma_{l}, \rho\right)}{\partial \rho} & =-\underbrace{\frac{\partial V_{l}\left(\alpha, \gamma, \tau_{-}\left(\sigma_{l} ; \rho\right)\right)}{\partial \tau_{-}}}_{+} \underbrace{\frac{\partial \tau_{-}}{\partial \rho}<0 .}_{+}
\end{aligned}
$$

Hence, if for some $\rho$ we have

$$
\begin{gathered}
\Delta_{V_{l}}\left(\sigma_{l}=0, \rho\right)>0, \\
\Delta_{V_{l}}\left(\sigma_{l} \rightarrow 1, \rho\right)<0,
\end{gathered}
$$

then there must exist a $\hat{\sigma}_{l} \in(0,1)$ such that

$$
\Delta_{V_{l}}\left(\sigma_{l}=\hat{\sigma}_{l}, \rho\right)=0
$$

and this defines a function $\rho=\rho\left(\hat{\sigma}_{l}\right)$ such that $\Delta_{V_{l}}\left(\hat{\sigma}_{l}, \rho\left(\sigma_{l}\right)\right)=0$. From implicit function theorem we know $\hat{\rho}\left(\sigma_{l}\right)$ strictly decreases in $\sigma_{l}$ :

$$
\frac{\partial \rho\left(\hat{\sigma}_{l}\right)}{\partial \hat{\sigma}_{l}}=-\frac{\frac{\partial \Delta_{V_{l}}\left(\sigma_{l}, \rho\right)}{\partial \sigma_{l}}}{\frac{\partial \Delta_{V_{l}}\left(\sigma_{l}, \rho\right)}{\partial \rho}}<0 .
$$

And, when $\gamma>\alpha$, from Lemma 2 we know that high type must strictly prefer signing up.

\section{Step 1.2}

We now ensure lenders' lender participation constraints, both before open banking and after open banking (regardless of facing borrowers who signed up or didn't). If

$$
\bar{r} \tau_{-}=\frac{\bar{r} \tau}{\frac{1-\sigma_{l}}{\rho}+\sigma_{l}} \geq 1-\beta,
$$

lender participation is satisfied for borrowers who did not sign up. Because $\tau_{-} \leq \tau \leq \tau_{+}$and $\beta<\alpha$, lenders are also willing to participate upon $H$ in the sign-up borrower pool and before open banking.

For any $\left(\hat{\sigma}_{l}, \rho\right)$ that satisfy $(51)$ (or $\rho=\rho\left(\hat{\sigma}_{l}\right)$ ), because $\tilde{V}_{l}^{-}$strictly increases in $\bar{r} \tau_{-},(52)$ is 
equivalent to

$$
\tilde{V}_{l}^{+}\left(\Gamma, \bar{r} ; \hat{\sigma}_{l}\right)=\tilde{V}_{l}^{-}\left(\Gamma, \bar{r}, \rho ; \hat{\sigma}_{l}\right) \geq 1-\alpha .
$$

The advantage of (53) is to derive a condition of $\hat{\sigma}_{l}$ to be satisfied that is free of $\rho$, which combined with $\rho=\rho\left(\hat{\sigma}_{l}\right)$ imply (52). As $\tilde{V}_{l}^{+}$strictly decreases in $\sigma_{l},(53)$ is equivalent to $\hat{\sigma}_{l} \leq \overline{\hat{q}}(\Gamma, \bar{r})$ and $\rho=\rho\left(\hat{\sigma}_{l}\right)$, where $\overline{\hat{q}}(\Gamma, \bar{r})$ is defined as

$$
\tilde{V}_{l}^{+}(\Gamma, \bar{r} ; \overline{\hat{q}}(\Gamma, \bar{r}))=1-\alpha \text {. }
$$

Then the resulting equilibrium satisfies $\sigma_{h}=1$ and

$$
\hat{\sigma}_{l} \in(0, \min (\overline{\hat{q}}(\Gamma, \bar{r}), 1)) .
$$

In sum, (55) translates to a non-empty set of $\rho=\rho\left(\hat{\sigma}_{l}\right),\left(\hat{\sigma}_{l}>0\right.$ says $\rho<\bar{\rho}(\Gamma, \bar{r}) \equiv \rho(0)$, which is equivalent to (49)) together with (50) that we will ensure later, we have shown the existence of the desired equilibrium.

\section{Step 2.}

We now impose conditions under which high-type to be hurt by open banking, i.e.,

$$
\tilde{V}_{h}(\Gamma, \bar{r})>\tilde{V}_{h}^{+}\left(\Gamma, \bar{r} ; \hat{\sigma}_{l}\right) .
$$

This implies that everyone is hurt by open banking: anyone who does not sign up is perceived to be of a lower average quality than the whole population, i.e., $\tau_{-}<\theta$, and thus worse off as $\frac{\partial V_{i}}{\partial \theta}>0$; l-type who signed up receive the same payoff as when they do not sign up, and thus also hurt by open banking. As $\frac{\partial \tilde{V}_{h}^{+}\left(\Gamma, \bar{r} ; \hat{\sigma}_{l}\right)}{\partial \hat{\sigma}_{l}}<0,(56)$ requires that

$$
\hat{\sigma}_{l}>z(\Gamma, \bar{r})
$$

where $z(\Gamma, \bar{r})$ is defined as $\tilde{V}_{h}(\Gamma, \bar{r})=\tilde{V}_{h}^{+}\left(\Gamma, \bar{r} ; \hat{\sigma}_{l}=z(\Gamma, \bar{r})\right)$. We know that $z>0 .{ }^{37}$ From (55), we need to make sure that $z<\min \left\{\overline{\hat{q}}_{\bar{q}}(\Gamma, \bar{r}), 1\right\}$. The condition for $z<1$ is

$$
\tilde{V}_{h}(\Gamma, \bar{r})>\tilde{V}_{h}^{+}\left(\Gamma, \bar{r} ; \hat{\sigma}_{l}=1\right) ;
$$

and the condition for $z<\overline{\hat{q}}(\Gamma, \bar{r})$ (defined in (54)), is

$$
\tilde{V}_{h}(\Gamma, \bar{r})>\tilde{V}_{h}^{+}\left(\Gamma, \bar{r} ; \hat{\sigma}_{l}=\overline{\hat{q}}(\Gamma, \bar{r})\right)
$$

\section{Step 2.1}

One can show that (57) implies our previous condition (50). (57) says

$$
\left(\bar{r}-\frac{1-\beta}{\tau}\right)(1-\phi(\bar{r} ; \alpha, \beta, \theta))>\left(\bar{r}-\frac{1-\alpha}{\tau}\right)(1-\phi(\bar{r} ; \alpha, \gamma, \theta)),
$$

\footnotetext{
${ }^{37}$ This is because $\tilde{V}_{h}(\Gamma, \bar{r})<\bar{r}-\frac{1-\beta}{\tau}<\tilde{V}_{h}^{+}\left(\Gamma, \bar{r} ; \hat{\sigma}_{l}=0\right)=\bar{r}-\frac{1-\alpha}{\tau}$.
} 
and since $\frac{1-\beta}{\tau}>\frac{1-\alpha}{\tau}$, we have $\phi(\bar{r} ; \alpha, \beta, \theta)<\phi(\bar{r} ; \alpha, \gamma, \theta)$. As a result (recall $\phi \in(0,1)$ and $\beta<\alpha<\gamma$, and third inequality uses $\phi(\bar{r} ; \alpha, \beta, \theta)<\phi(\bar{r} ; \alpha, \gamma, \theta))$

$$
\begin{aligned}
\tilde{V}_{l}^{+}\left(\Gamma, \bar{r} ; \sigma_{l}=1\right) & =1-\gamma[\alpha+(1-\alpha) \cdot \phi(\bar{r} ; \alpha, \gamma, \theta)] \\
& <1-\alpha[\alpha+(1-\alpha) \cdot \phi(\bar{r} ; \alpha, \gamma, \theta)] \\
& <1-\alpha[\beta+(1-\beta) \cdot \phi(\bar{r} ; \alpha, \gamma, \theta)] \\
& <1-\alpha[\beta+(1-\beta) \cdot \phi(\bar{r} ; \alpha, \beta, \theta)] \\
& =\tilde{V}_{l}^{-}\left(\Gamma, \bar{r}, \rho ; \sigma_{l}=1\right) .
\end{aligned}
$$

\section{Step 2.2}

We now show that (57) and (58) correspond to a non-empty set of $\{\Gamma, \bar{r}\}$. Let $R(\bar{r}) \equiv \frac{\bar{r} \tau}{1-\beta}-1>$ 0 , which can be viewed as a function of $\bar{r}$ given other parameters. (57) is equivalent to

$$
G_{1}(R ; \alpha, \beta, \gamma) \equiv\left(\gamma \frac{1-\alpha}{1-\beta}-\frac{\alpha-\beta}{1-\beta}-\alpha\right) R^{2}-\left(\frac{\alpha-\beta}{1-\beta}\right)\left[\left(\frac{\alpha-\beta}{1-\beta}\right)+2 \alpha\right] R-\alpha\left(\frac{\alpha-\beta}{1-\beta}\right)^{2}>0
$$

and (58) is equivalent to

$$
G_{2}(R ; \alpha, \gamma) \equiv R^{2}-\frac{(\gamma-\alpha)^{2}(\alpha+1)}{\alpha(1-\gamma)(1+\gamma-2 \alpha)} \cdot R-\frac{(\gamma-\alpha)^{2}}{(1-\gamma)(1+\gamma-2 \alpha)}>0 .
$$

38

Our goal is to give a condition on $R$ so that both (59) and (60) hold. A necessary condition for (59) is that

$$
\beta>\beta_{1}(\alpha, \gamma) \equiv \frac{2 \alpha-\gamma(1-\alpha)}{1+\alpha},
$$

under which we have $\gamma \frac{1-\alpha}{1-\beta}-\frac{\alpha-\beta}{1-\beta}-\alpha>0$. Then, because both $G_{1}(R)=0$ and $G_{2}(R)=0$ are quadratic functions with one negative root and one positive root, the condition that we are after is

$$
R(\bar{r})>\max \left\{R_{1}(\alpha, \beta, \gamma), R_{2}(\alpha, \gamma)\right\},
$$

where $R_{1}(\alpha, \beta, \gamma)$ is the positive root of $G_{1}(R ; \alpha, \beta, \gamma)=0$ and $R_{2}(\alpha, \gamma)$ is the positive root of $G_{2}(R ; \alpha, \gamma)=0$.

\footnotetext{
${ }^{38}$ Plug (54) into (58) we have $\frac{R^{2}}{(R+1)(R+\alpha)}>\left[1-\frac{1}{\frac{\gamma^{2}(1-\alpha)}{\alpha(1-\gamma)}+1-\gamma}\right]\left[1-\frac{\alpha(1-\gamma)}{\gamma(1-\alpha)}\right]$. Because

$$
0<\left[1-\frac{1}{\underbrace{\frac{\gamma^{2}(1-\alpha)}{\alpha(1-\gamma)}}_{>\gamma}+1-\gamma}\right][1-\underbrace{\frac{\alpha(1-\gamma)}{\gamma(1-\alpha)}}_{<1}]<1
$$
}

this corresponds to an inequality that says an upward quadratic function of $R$ is positive. 


\section{Step 3.}

To sum up, if $\{\Gamma, \rho, \bar{r}\}$ satisfy conditions i) $\gamma>\alpha>\beta>\beta_{1}(\alpha, \gamma) \equiv \frac{2 \alpha-\gamma(1-\alpha)}{1+\alpha}$, ii) (57) and (58) for $\bar{r}$, which is summarized by $(61)$, and finally iii) $\hat{\sigma}_{l} \in\left(z(\Gamma, \bar{r}), \min \left(\frac{\overline{\hat{q}}}{\hat{q}}(\Gamma, \bar{r}), 1\right)\right)$ that imply a compact set of $\rho=\rho\left(\hat{\sigma}_{l}\right)$, then there exists an equilibrium such that $\sigma_{h}=1, \sigma_{l} \in(0,1)$, and everyone is hurt by open banking

\section{B.2.2 Proof of Proposition 4 Part 1 (Uniqueness)}

Generally there are nine possible types of equilibrium under the binary sign-up cost specification:

$$
\begin{array}{lll}
{\left[\sigma_{h}=1, \sigma_{l}=1\right]} & {\left[\boldsymbol{\sigma}_{\boldsymbol{h}}=\mathbf{1}, \boldsymbol{\sigma}_{\boldsymbol{l}} \in \mathbf{( 0 , 1 )}\right]} & {\left[\sigma_{h}=1, \sigma_{l}=0\right]} \\
{\left[\sigma_{h} \in(0,1), \sigma_{l}=1\right]} & {\left[\sigma_{h} \in(0,1), \sigma_{l} \in(0,1)\right]} & {\left[\sigma_{h} \in(0,1), \sigma_{l}=0\right]} \\
{\left[\sigma_{h}=0, \sigma_{l}=1\right]} & {\left[\sigma_{h}=0, \sigma_{l} \in(0,1)\right]} & {\left[\sigma_{h}=0, \sigma_{l}=0\right]}
\end{array}
$$

where the equilibrium that we construct is boldfaced. Notice that $\left[\sigma_{h}=0, \sigma_{l}=0\right]$ could be supported by any consistent off-equilibrium belief of $\theta_{+}$. In this part, we argue that if (62) holds additionally, then except for the special equilibrium $\left[\sigma_{h}=0, \sigma_{l}=0\right]$, the equilibrium constructed in Part 1 is unique.

The additional condition we need for uniqueness is

$$
R(\bar{r})<R_{3}(\alpha, \beta, \gamma) \equiv \alpha\left(\frac{1-\gamma}{\gamma-\beta}\right)
$$

which is equivalent to

$$
V_{l}\left(\alpha, \gamma, \theta_{+}=1\right)>V_{l}(\alpha, \beta, \theta)
$$

once we plug in borrower surplus (9) and (10). Note that even when $\theta_{+}=1$, we assume that firms still screen the consumer who signs up. As there is no cost in screening, this assumption leads to a more general argument, whereas (63) is automatically satisfied if firms do not screen and always serve the sign-up consumer given $\theta_{+}=1$. (63) says $l(0)$ will sign on if he is perceived to be $h$-type when doing so, relative to being perceived as the average type $\theta$ by not signing on.

We need to verify that the set of primitive parameters that satisfies all the sufficient conditions is non-empty. In light of (61), we need that

$$
R_{3}(\alpha, \beta, \gamma)>\max \left\{R_{1}(\alpha, \beta, \gamma), R_{2}(\alpha, \gamma)\right\}
$$

and we aim to provide a sufficient condition under which (64) holds.

For any $\gamma>\alpha$, if $\beta=\alpha$, we have $R_{1}(\alpha, \beta=\alpha, \gamma)=0<R_{2}(\alpha, \gamma)$. Recall that for $R>$ $R_{1}(\alpha, \beta, \gamma)$ to be sufficient for (59), we need $\beta>\beta_{1}(\alpha, \gamma) \equiv \frac{2 \alpha-\gamma(1-\alpha)}{1+\alpha}$ with $\beta_{1}(\alpha, \gamma)<\alpha$. Note that we have $R_{1}\left(\alpha, \beta \rightarrow \beta_{1}(\alpha, \gamma)^{+}, \gamma\right)=+\infty>R_{2}(\alpha, \gamma)$. Define

$$
\hat{\beta}(\alpha, \gamma) \equiv \sup \left\{\beta: R_{1}(\alpha, \beta, \gamma)=R_{2}(\alpha, \gamma), \beta_{1}(\alpha, \gamma)<\beta<\alpha\right\}
$$


which must satisfy $\beta_{1}(\alpha, \gamma)<\hat{\beta}(\alpha, \gamma)<\alpha$ strictly. Then when $\beta \in(\hat{\beta}(\alpha, \gamma), \alpha)$, we have $R_{2}(\alpha, \gamma)>R_{1}(\alpha, \beta, \gamma)$, and therefore (64) is equivalent to

$$
R_{3}(\alpha, \beta, \gamma)>R_{2}(\alpha, \gamma)
$$

Note that $\frac{\partial R_{3}(\alpha, \beta, \gamma)}{\partial \beta}>0$; then a sufficient condition for $(66)$ where $\beta>\hat{\beta}(\alpha, \gamma)>\beta_{1}(\alpha, \gamma)$ is

$$
R_{3}\left(\alpha, \beta_{1}(\alpha, \gamma), \gamma\right)>R_{2}(\alpha, \gamma)
$$

The condition (67) only involves $\alpha$ and $\gamma$, and we derive the restriction on the space of $\{\alpha, \gamma\}$ so that (67) holds.

Because $R_{3}\left(\alpha, \beta_{1}(\alpha, \gamma), \gamma\right)=\frac{\alpha(1-\gamma)(1+\alpha)}{2(\gamma-\alpha)}>0$, and $G_{2}(R)=0$ is a quadratic function with one negative root and one positive root, (67) is equivalent to

$$
\begin{aligned}
G_{2}\left(R_{3}\left(\alpha, \beta_{1}(\alpha, \gamma), \gamma\right)\right) & =\frac{\alpha^{2}(1-\gamma)^{2}(1+\alpha)^{2}}{4(\gamma-\alpha)^{2}}-\frac{(\gamma-\alpha)(\alpha+1)^{2}}{2(1+\gamma-2 \alpha)}-\frac{(\gamma-\alpha)^{2}}{(1-\gamma)(1+\gamma-2 \alpha)} \\
& \equiv \tilde{G}_{2}(\gamma ; \alpha)>0
\end{aligned}
$$

One can easily show $\frac{\partial \tilde{G}_{2}(\gamma ; \alpha)}{\partial \gamma}<0 .{ }^{39}$ Together with

$$
\lim _{\gamma \rightarrow \alpha^{-}} G_{2}\left(R_{3}\left(\alpha, \beta_{1}(\alpha, \gamma), \gamma\right)\right) \rightarrow+\infty
$$

we know there exists a $\hat{\gamma}(\alpha)>\alpha$ such that when $\alpha<\gamma<\hat{\gamma}(\alpha)$, (67) is satisfied.

\footnotetext{
${ }^{39}$ Let $g_{1}(\gamma ; \alpha) \equiv \frac{1-\gamma}{\gamma-\alpha}$, and $g_{2}(\gamma ; \alpha)=\frac{\gamma-\alpha}{1+\gamma-2 \alpha}$; then with $1>\gamma>\alpha>0$ we have

$$
\frac{\partial g_{1}(\gamma ; \alpha)}{\partial \gamma}<0, \frac{\partial g_{2}(\gamma ; \alpha)}{\partial \gamma}>0
$$
}

As a result, the following function is strictly decreases in $\gamma$ :

$$
\tilde{G}_{2}(\gamma ; \alpha)=\frac{\alpha^{2}(1+\alpha)^{2}}{4} \cdot g_{1}(\gamma ; \alpha)^{2}-\frac{(1+\alpha)^{2}}{2} \cdot g_{2}(\gamma ; \alpha)-\frac{g_{2}(\gamma ; \alpha)}{g_{1}(\gamma ; \alpha)} .
$$

